This document is confidential and is proprietary to the American Chemical Society and its authors. Do not copy or disclose without written permission. If you have received this item in error, notify the sender and delete all copies.

\title{
A transcriptomic Analysis of the Activity and Mechanism of Action of a Ruthenium(II)-Based Antimicrobial That Induces Minimal Evolution of Pathogen Resistance
}

\begin{tabular}{|r|l|}
\hline Journal: & ACS Pharmacology \& Translational Science \\
\hline Manuscript ID & pt-2020-00159c.R1 \\
\hline Manuscript Type: & Article \\
\hline Author: & 19-Nov-2020 \\
\hline Complete List of Authors: & $\begin{array}{l}\text { Varney, Adam; Nottingham Trent University, Biosciences } \\
\text { Smitten, Kirsty; University of Sheffield, Department of Chemistry } \\
\text { Thomas, Jim; University of Sheffield, Department of Chemistry } \\
\text { McLean, Samantha; Nottingham Trent University, Biosciences }\end{array}$ \\
\hline
\end{tabular}

\section{SCHOLARONE Manuscripts}




\title{
A transcriptomic Analysis of the Activity and \\ Mechanism of Action of a Ruthenium(II)-Based
}

\section{Antimicrobial That Induces Minimal Evolution of}

\author{
Pathogen Resistance
}

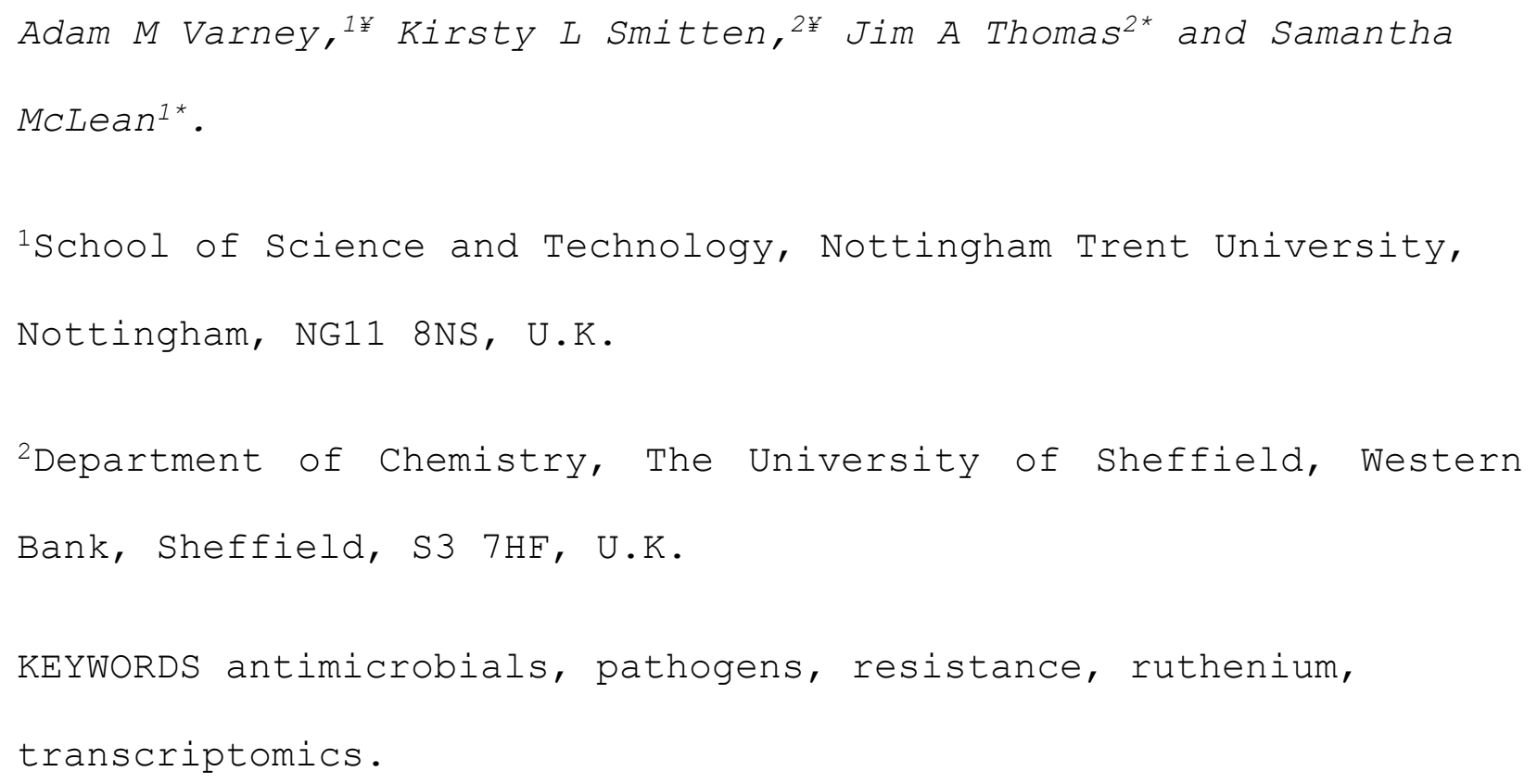


treatment. Previously, we have reported on the therapeutic activity of a dinuclear ruthenium (II) complex against pathogenic, multidrug resistant bacterial pathogens. Herein, we report that the solubility properties of this lead are comparable to those exhibited by orally available therapeutics, that - in comparison to clinically relevant antibiotics - it induces very slow evolution of resistance in the uropathogenic, therapeutically resistant, $E$. coli strain EC958 and this resistance was lost when exposure to the compound was temporarily removed. With the aim of further investigating the mechanism of action of this compound, the regulation of nine target genes relating to the membrane, DNA damage and other stress responses provoked by exposure to the compound was also studied. This analysis confirmed that the compound causes a significant transcriptional downregulation of genes involved in membrane transport and the tricarboxylic acid cycle. By contrast, expression of the chaperone protein-coding gene, spy, was significantly increased suggesting a requirement for repair of damaged proteins in the region of the outer membrane. The complex was also found to display activity comparable to that in $E$. coli in a range of other therapeutically relevant Gramnegative pathogens.

ACS Paragon Plus Environment 
Over recent years, there has been a significant increase in bacterial infections that display multidrug resistance, leading to a concomitant increase in mortality rates. ${ }^{1-3}$ As last-line treatments such as carbapenems increasingly fail, ${ }^{3-6}$ antimicrobial resistance is rapidly becoming a global threat to public health and the economy. ${ }^{7-9}$ It has been estimated that by 2050 ten million lives per year and a cumulative \$100 trillion of economic output will be lost due to the rise of drug-resistant infections. ${ }^{10}$

Escherichia coli strains are a significant cause of infection within clinical settings and are linked to high morbidity and mortality globally causing a wide range of infections including meningitis, pneumonia and bacteraemia. ${ }^{11} \mathrm{E}$. coli is highly prevalent in urinary tract infections and accounts for $80 \%$ of all community acquired urinary tract infections. ${ }^{12,13}$ High antimicrobial resistance within uropathogenic E. coli (UPEC) strains is common; a study of antibiotic resistance in cases of urinary tract infections in Nigeria found that from a total of 137 E. Coli isolates 36 \% were resistant to ten out of 11 urine line antibiotics. ${ }^{14}$

In this context, UPEC sequence type ST131 is an emerging pathogen of particular concern. Apart from being commonly resistant to fluoroquinolones, this strain produces the CTX-M extended spectrum beta lactamase that confers resistance to oxyimino-cephalosporins 
and monobactams. ${ }^{15-18}$ Furthermore, CTX-M encoding genes are found on plasmids which frequently carry additional resistance genes. As a consequence, geographical variants commonly possess quinolone modifying enzymes that provide fluroquinolone resistance, as well as the enzymes carbapenemases and cephamycinases. ${ }^{19}$

As global concern increased, the USA surveillance programs SENTRY and MYSTIC estimated through extrapolation that ST131 accounted for approximately 17 of all E. coli isolates, 44 of all antimicrobial resistant isolates and around 68 of fluoroquinolone resistant isolates.16,20. This is problematic as within the US fluroquinolones are prescribed as a first line treatment against urinary tract infections. Given these facts, it is unsurprising that - even when treated with standard antibiotic regimes - urinary tract infections caused by ST131 can dangerously progress into pyelonephritis and sepsis. ${ }^{21,22}$

With one third of women having a course of antibiotics to treat a urinary tract infection by the age of $26^{23}$ multidrug resistant uropathogenic bacteria are clearly a significant threat, with ST131 being at the forefront of concern. It is therefore apparent that urine line antibiotics are a pivotal tool in healthcare and, as they are quickly becoming less effective, it is crucial that novel treatment options are identified. ${ }^{24}$

Metal complexes are a class of compounds that demonstrated significant early promise as therapeutic leads but are 
underdeveloped. As early as the 1950s, the Dwyer group reported that $\mathrm{Ru}^{\mathrm{II}}$ polypyridyl complexes had potential as antimicrobials.25,26 Their work demonstrated that increasing the lipophilicity of the parent $\left[\mathrm{Ru}(\mathrm{phen})_{3}\right]^{2+}$ cation resulted in enhanced antimicrobial action, leading to a derivative that displayed promising activity against Gram-positive bacteria. However, due to the wide range of effective conventional antibiotics clinically available at that time, no further development of these distinctive leads occurred for decades.

In the last decade or so, due to the growing antibiotic resistance crisis, the use of metals as antimicrobials has been revisited, ${ }^{27-32}$ with particular focus on the $\mathrm{Ru}$ II systems, 28,33 although most of these newly reported systems still exhibit higher activities against Gram-positive bacteria. As part of a program to develop novel metal-complex-based imaging probes, ${ }^{34-36}$ therapeutics ${ }^{37-40}$ and phototherapeutics, ${ }^{41-45}$ we recently identified a series of dinuclear ruthenium (II) complexes that exhibit higher activity against Gram-negative species. ${ }^{46}$ Subsequent detailed studies involving several strains of Staphylococcus aureus indicated that the lowered activity against Gram-positive bacteria is due to the complexes binding to cell wall teichoic acids residues, leading to reduced internalization. ${ }^{47}$

Although these reports provided preliminarily insights into the mechanism of action of these new potential therapeutics, in this 
study a deeper and more focused understanding of the antimicrobial activity of the main lead complex, $\mathbf{1}^{4+}$ (Figure 1 ) is developed. The complex was synthesized as a $\mathrm{PF}_{6}$, for biological studies anion metathesis was used to convert the complex into the $\mathrm{Cl}^{-}$salt form. Using the multidrug resistant uropathogenic strain of $E$. coli as a model Gram-negative pathogen quantitative PCR (qPCR) was used to monitor the regulation of key genes thought to be responsible for sensing and reacting to the presence of $\mathbf{1}^{4+}$, providing further insights into its mechanism of action. As we also find the complex displays solubility that is comparable with established orally available therapeutics, is active against a range of Gram-negative pathogens, and resistance towards it emerges only very slowly, these data further underlines its therapeutic potential.

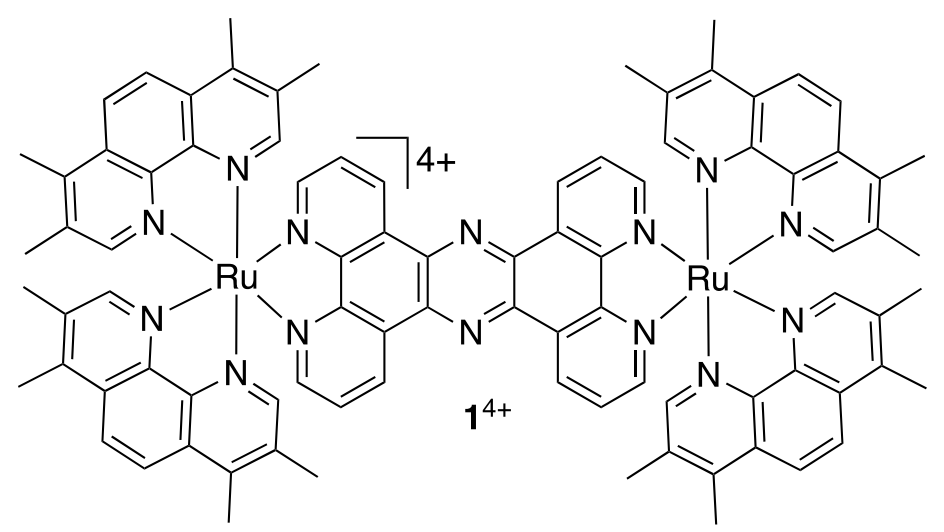

Figure 1. Structure of the ruthenium (II) complex relevant to this report. 


\section{Results}

\section{Kinetic Turbidimetric Solubility}

Over the last two decades, largely as a consequence of high through-put screening and demand for structurally complex drug leads, poor aqueous solubility has increasingly become a limiting development factor in drug development; compounds with poor solubility present high attrition risks and increased drug development costs. ${ }^{48-50}$ As complex $1^{4+}$ displays activity against Gram-negative pathogens, and it is known that solubility is a key criterion for oral availability of any drug lead, 51 its solubility was assessed through kinetic turbidimetric stability assays (Figure 2).

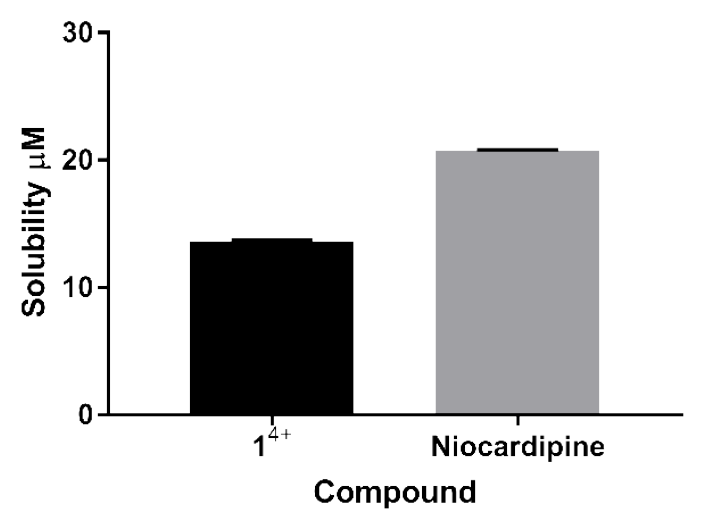

\begin{tabular}{|l|l|l|l|}
\hline Compound & LogS & Solubility/ $\boldsymbol{\mu M}$ & Result \\
\hline $\mathbf{1}^{4+}$ & 1.138 & 13.7 & Pass \\
\hline Nicardipine & 1.318 & 20.8 & Pass \\
\hline
\end{tabular}

Figure 2. Kinetic turbidimetric solubility. The kinetic solubility of $\mathbf{1}^{4+}$ measured through turbidimetry and compared with a positive control nicardipine. Turbidimetry was measured at 7 controls $(0.2$ - $100 \mu \mathrm{M})$ in DMSO (1 \%). Samples were incubated for 5 minutes at 
$25^{\circ} \mathrm{C}$. Absorbance determined at $620 \mathrm{~nm} . \mathrm{N}=4 \pm \mathrm{SD}$. Any complex with a solubility of $<1 \mu \mathrm{M}$ is considered insoluble and therefore fails the solubility assay.

Nicardipine - a drug used to treat high blood pressure and angina, that is frequently employed in drug metabolism and pharmacokinetic studies - was used as a positive control and it was found that $\mathbf{1}^{4+}$ exhibits solubility in the range of this control - see SI for details. Under the Biopharmaceutics Classification System provided by the FDA, which is used to predict intestinal drug absorption, $[1] \mathrm{Cl}_{4}$ is seen to be freely soluble ${ }^{52}$. As aqueous solubility is a major factor in the bioavailability of antimicrobial compounds; the high solubility of $1^{4+}$ indicates that it is a good orally delivered drug candidate.

\section{Resistance of Escherichia coli EC958 to clinical antibiotics}

The uropathogenic E. Coli strain EC958 used in this study is a sequence type ST131 isolate. Due to the presence of the extendedspectrum $\beta$-lactamase gene blaCTX-M-15 on its pEC958 virulence plasmid it has been designated as a Priority 1: Critical Pathogen by the World Health Organization that urgently requires new treatments. ${ }^{18}$ To confirm the categorization and antibiotic resistance profile of this EC958 clinical isolate, phenotypic testing of its sensitivity to several $\beta$-lactam antibiotics was carried out. These studies - which included a monobactam and different generations of cephalosporins, as well as various other 
major groups of antibiotics - were accomplished through a standardized EUCAST disc diffusion assay (Table 1). ${ }^{53}$

The tests revealed that the strain shows resistance to all tested cephalosporins and the monobactam; aztreonam, thus confirming its Priority 1 categorization; however, it is still sensitive to carbapenems, tigecycline, fosfomycin and nitrofurantoin.

Table 1. EUCAST disc diffusion antibiotic sensitivity testing against E. COli strain EC958

\begin{tabular}{|c|c|c|c|c|}
\hline Antibiotic & $\begin{array}{c}\text { Disk } \\
(\mu g)\end{array}$ & content & $\begin{array}{ll}\text { Mean } & \text { zone } \\
\text { diameter } & (\mathrm{mm}) \\
\pm \text { SEM } & \end{array}$ & Sensitivity* \\
\hline \multicolumn{5}{|c|}{ Cephalosporins } \\
\hline Cefotaxime & 3 & & $10 \pm 0$ & Resistant \\
\hline Ceftazidime & 30 & & $9.5 \pm 0.47$ & Resistant \\
\hline Cefuroxime & 30 & & $0 \pm 0$ & Resistant \\
\hline \multicolumn{5}{|c|}{ Tetracyclines } \\
\hline Tigecycline & 15 & & $23 \pm 0$ & Sensitive \\
\hline \multicolumn{5}{|l|}{ Monobactams } \\
\hline Aztreonam & 30 & & $19.5 \pm 0.47$ & Resistant \\
\hline
\end{tabular}




\begin{tabular}{|c|c|c|c|}
\hline \multicolumn{4}{|l|}{ Carbapenems } \\
\hline Doripenem & 10 & $29 \pm 0$ & Sensitive\# \\
\hline Meropenem & 10 & $31.5 \pm 0.47$ & Sensitive \\
\hline Ertapenem & 10 & $26 \pm 0.47$ & Sensitive \\
\hline Imipenem & 10 & $29.7 \pm 0.47$ & Sensitive \\
\hline \multicolumn{4}{|l|}{ Aminoglycosides } \\
\hline Gentamicin & 10 & $15 \pm 0$ & Resistant \\
\hline \multicolumn{4}{|c|}{ Fluoroquinolones } \\
\hline Ciprofloxacin & 5 & $0 \pm 0$ & Resistant \\
\hline Levofloxacin & 5 & $0 \pm 0$ & Resistant \\
\hline \multicolumn{4}{|l|}{ Miscellaneous } \\
\hline Rifampicin & 2 & $0 \pm 0$ & Resistant \\
\hline Fosfomycin & 50 & $28.5 \pm 0.82$ & Sensitive \\
\hline Nitrofurantoin & 100 & $22 \pm 0$ & Sensitive \\
\hline
\end{tabular}

* Sensitivity or resistance determined by EUCAST breakpoint figures, 201954. "Sensitivity or resistance determined by EUCAST breakpoint figures, $2018^{55}$

\section{Growth and viability of growing E. coli strain EC958 cultures is diminished upon exposure to $\mathbf{1}^{4+}$}

Having established the multidrug resistance properties of the model EC958 strain, we investigated its sensitivity to complex, $\mathbf{1}^{4+}$. Previously, we determined that the minimal inhibitory concentration (MIC) of $1^{4+}$ was $2.8 \mu \mathrm{M}^{46}$, however the MIC is measured using very low turbidity cultures recently diluted from stationary phase. As treatment of most infections occurs when the bacterial load is already high and actively growing, we investigated what effects exposure to the compound had on actively growing cultures. Growth assays in which cultures in the early-exponential growth 
phase were injected with a range of concentrations of $\mathbf{1}^{4+}$ below and above the MIC were performed. As Figure 3 illustrates, very little effect on growth is observed within the first 30 minutes of exposure to the compound. Subsequently, growth in the presence of $1^{4+}$ becomes inhibited for at least $2.5 \mathrm{~h}$ and the extent of growth inhibition correlates with increasing concentration of the compound. After this period, there is some recovery at concentrations up to $1 \mu \mathrm{M}$, but above this concentration little recovery in growth is seen. To understand whether $\mathbf{1}^{4+}$ was affecting viability or causing bacteriostasis at these concentrations, viability assays were performed (Figure 3B). From 2 h postinjection, a significant difference in viability is observed between untreated cultures and those exposed to $0.5-5 \mu \mathrm{M}$ of $\mathbf{1}^{4+}$. In agreement with this data, fluorescence microscopy shows accumulation of the $\mathrm{Ru}^{\mathrm{II}}$ complex between 20 and 120 minutes and a significant increase in fluorescence at the 60- to 120-minute timepoints, indicating further accumulation of the compound (Figure 3C). Increase in fluorescence intensity was measured using the integrated density measurement function on ImageJ. At 60 minutes the average corrected total cell fluorescence (CTCF) for the cells was 9308.9, at 120 minutes the average CTCF for the cells was 29956.9. This is in agreement with previous findings indicating that ruthenium accumulates within the cell during this time. ${ }^{46}$ 


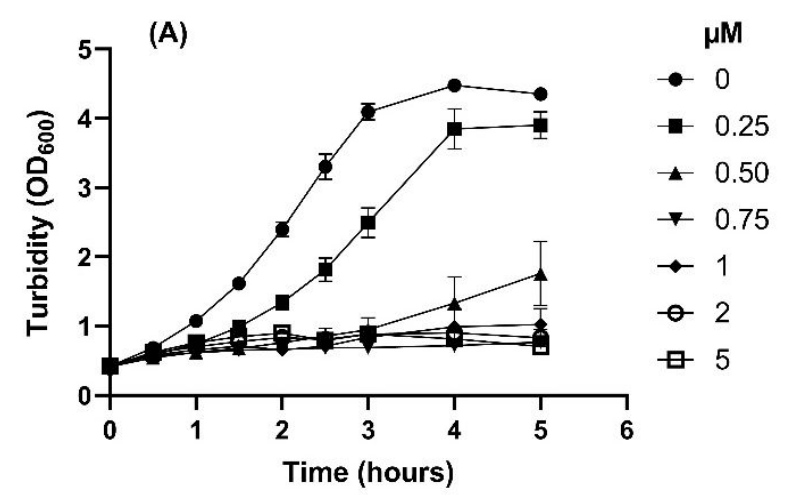

(C)

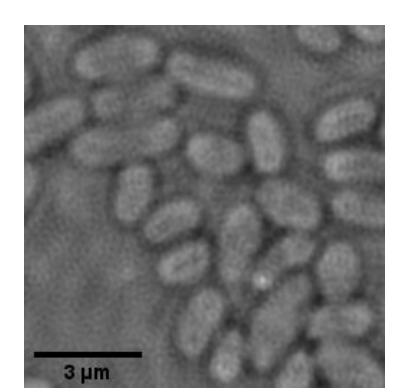

0 min

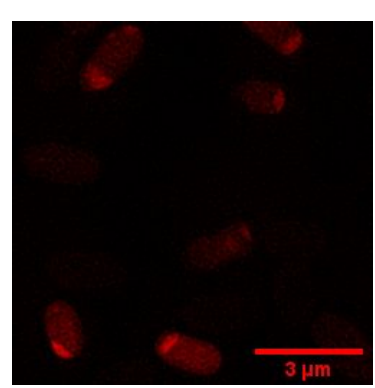

$20 \min$

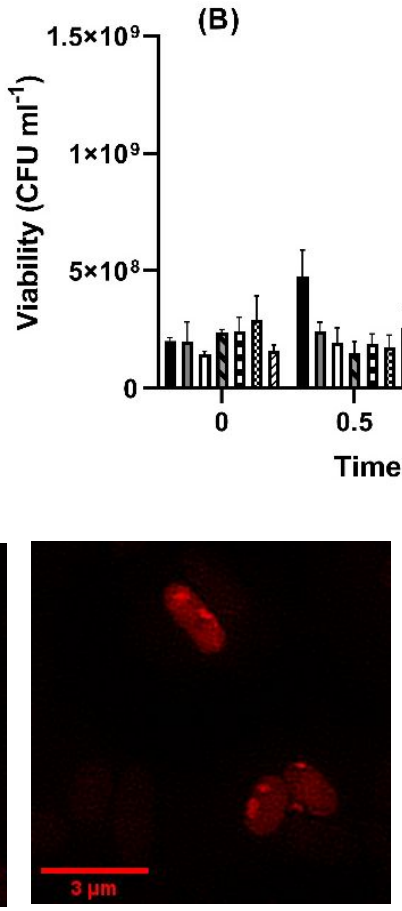

$60 \min$

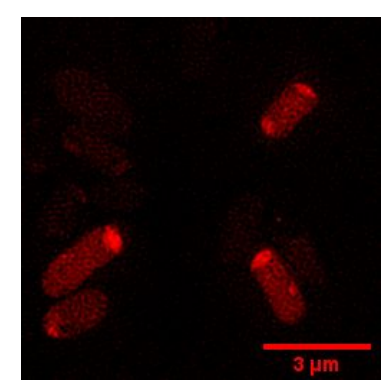

$120 \mathrm{~min}$

Figure 3. Effect of $\mathbf{1}^{4+}$ concentration on the growth and viability of E. coli strain EC958 in glucose defined minimal medium (A) Cultures were grown to early-exponential phase at $37{ }^{\circ} \mathrm{C}$ and 150 rpm shaking in $250 \mathrm{ml}$ flasks with defined minimal medium containing glucose as the sole carbon source. Upon reaching an $\mathrm{OD}_{600}$ of 0.4 differing concentrations of $1^{4+}(0-5 \mu \mathrm{M})$ were added to the cultures and growth was monitored at regular intervals. $\mathrm{N} \geq 3 \pm$ SEM. (B) Samples of the cultures described in (A) were removed and viable counts performed to determine the bactericidal effect of $\mathbf{1}^{4+}$ at differing concentrations between $0-5 \mu \mathrm{M} . \mathrm{N} \geq 3 \pm \mathrm{SEM}$. Statistical significance $(* *)$ was determined with two-way ANovA and Tukey's multiple comparisons ( $<$ <.05). (C) Localization of $1^{4+}$ in E. Coli EC958 cells was visualized through structured 
illumination microscopy at 0-, 20-, 60- and 120-min. Cells were imaged using the emission of ${1^{4+}}^{4}$ excitation at $450 \mathrm{~nm}$ using $\mathrm{A} 568$ filter. After treatment with $0.8 \mu \mathrm{M} 1^{4+}$ cells were washed with nitric acid before fixing with paraformaldehyde (4 \%). Images were taken using a 1516 oil and SlowFade ${ }^{\mathrm{TM}}$ Gold Antifade Mountant.

\section{Evolution of resistance of E. coli strain EC958 to $\mathbf{1}^{4+}$}

The potential of $\mathbf{1}^{4+}$ as a putative antimicrobial lead would be enhanced if therapeutic resistance does not develop rapidly, nor to a high degree. To investigate this, we serially passaged EC958 cultures containing concentrations of $1^{4+}$ at half the minimal inhibitory concentration for five weeks. The WT MIC in minimal media $(1.5 \mu \mathrm{M})$ was used for initiation of the experiment, new MIC assays were undertaken each week and changes to $\mathbf{1}^{4+}$ concentrations were made if an MIC increase was observed to maintain the $0.5 \mathrm{x}$ MIC concentration in the growing cultures (Figure 4).

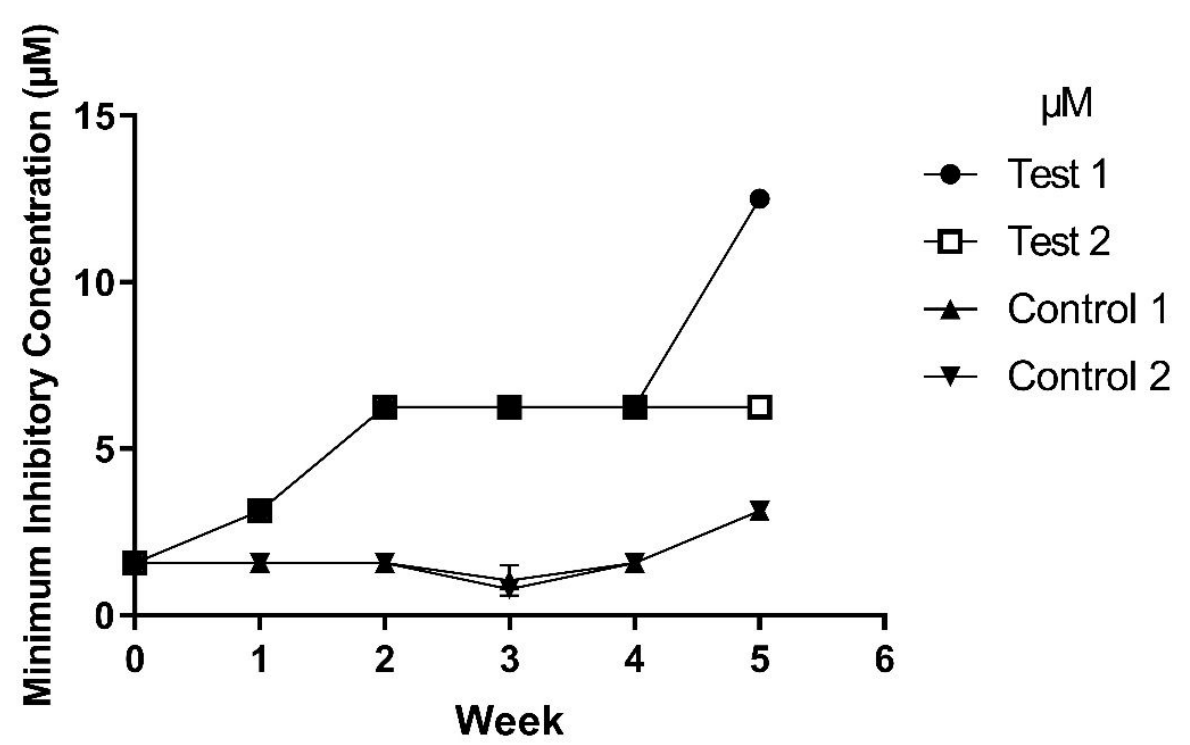

ACS Paragon Plus Environment 
Figure 4. Evolution of $\mathbf{1}^{4+}$ resistance of $E$. Coli strain EC958 in glucose defined minimal media. E. coli cultures were grown in liquid GDMM containing $0.5 \times$ MIC of $\mathbf{1}^{4+}$, cultures were passaged every $24 \mathrm{~h}$ and weekly MIC's were determined. Experiments were performed as biological duplicates and results displayed are weekly mean MIC results ( $\geq 3 \pm S D$ for each biological repeat). Control samples (upward and downward facing triangles) were treated the same as test samples $(\bullet, \square)$, except no compound was added. Two-Way ANOVA with Tukey's multiple comparison test showed significant differences between the original WT cultures and both test cultures by week five and between the test and control cultures in week five $(\mathrm{p}<0.0001)$.

Both independent cultures that were passaged in the presence of $\mathbf{1}^{4+}$ showed a small increase in resistance over the first two weeks of exposure with the MIC increasing from $1.5 \mu \mathrm{M}$ to $6.1 \mu \mathrm{M}$. A further increase in resistance was observed in one of the test cultures after five weeks of exposure (MIC: $12.5 \mu \mathrm{M}$ ) whereas resistance in the other test culture remained constant between weeks two and week five. Significant differences were found between both test cultures after five weeks exposure to $\mathbf{1}^{4+}$ compared with the initial MIC of the WT strain $(\mathrm{p}<0.001)$. We observed a fourto eight-fold increase in MIC over the course of five weeks constant exposure to $\mathbf{1}^{4+}$. Additionally, tests were performed to 
determine whether resistance would evolve to $\mathbf{1}^{4+}$ due to serial passage in the absence of the ruthenium complex. Figure 4 shows a minor increase in resistance to the compound in week five where $\mathbf{1}^{4+}$ was omitted, however this is a small increase, suggesting exposure to the ruthenium complex is required to cause significant resistance to $\mathbf{1}^{4+}$.

Samples from all cultures were streaked weekly to check for morphological changes or contaminants. Cultures exposed to the RuII complex consistently showed different colony size and morphology when subsequently streaked onto rich media in the absence of $\mathbf{1}^{4+}$ (Figure S-1). This effect was transient, as re-streaking of the different sized colonies subsequently produced normal growth (data not shown).

All cultures in the evolution experiment depicted in Figure 4 were cryopreserved weekly. When cultures that had demonstrated a four- to eight-fold increase in MIC were revived from these frozen stocks and $\mathbf{1}^{4+}$ susceptibility was retested, the MIC was reduced to WT levels. This indicates that the strains may not have become resistant to $\mathbf{1}^{4+}$ via mutational change, instead it suggests that altered expression of resistance genes such as those coding for efflux pumps and modulated membrane permeability may be the cause of the small increase in resistance after prolonged exposure to $\mathbf{1}^{4+}$. Upon re-streaking from resistant cryopreserved stocks, these 
genes appear to revert to their pre-exposure expression levels, resulting in the reduction in MIC to the original value.

\section{Transcriptomic analysis reveals that membrane repair plays a significant role in the response to $\mathbf{1}^{4+}$ exposure}

To further study the effects of $1^{4+}$ on $E$. coli strain EC958 its mechanism of action was probed through quantitative PCR. From the study on bacterial growth after exposure to a range of concentrations of $\mathbf{1}^{4+}$ illustrated in Figure 3, we determined that a final RuII complex concentration of $1.5 \mu \mathrm{M}$ would allow gene expression to be accurately assessed. Significant cell death occurs within 60-minutes of treatment when a lethal dose of the compound is administered. We therefore monitored changes in gene expression at timepoints ranging from 20 to 120 minutes to determine whether early changes in the response to the compound are altered after continued exposure.

Cultures in glucose defined minimal media were grown in triplicate to early-exponential phase, after which samples of the culture were removed to act as the pre-exposure control. Subsequently, at each timepoint, post-exposure samples were removed from the culture, RNA was extracted, and the expression of selected genes was compared to a reference.

Prompted by our initial experiments indicating a dual mechanism of action of $\mathbf{1}^{4+}, 46$ the nine target genes selected for study have functional roles in membrane permeability/stability and DNA repair and a qPCR analysis was performed at all timepoints to assess 
expression of these genes after exposure to $\mathbf{1}^{4+}$. The reference gene hcat was selected for this study as it is a well-defined, constitutively expressed, gene under many conditions and showed no significant change in expression in whole-transcriptome analyses of E. coli exposed to other ruthenium-based compounds. 56 In these experiments, it was found that three of the nine genes tested showed significant changes in expression upon exposure to $\mathbf{1}^{4+}$ ( Figure 5).

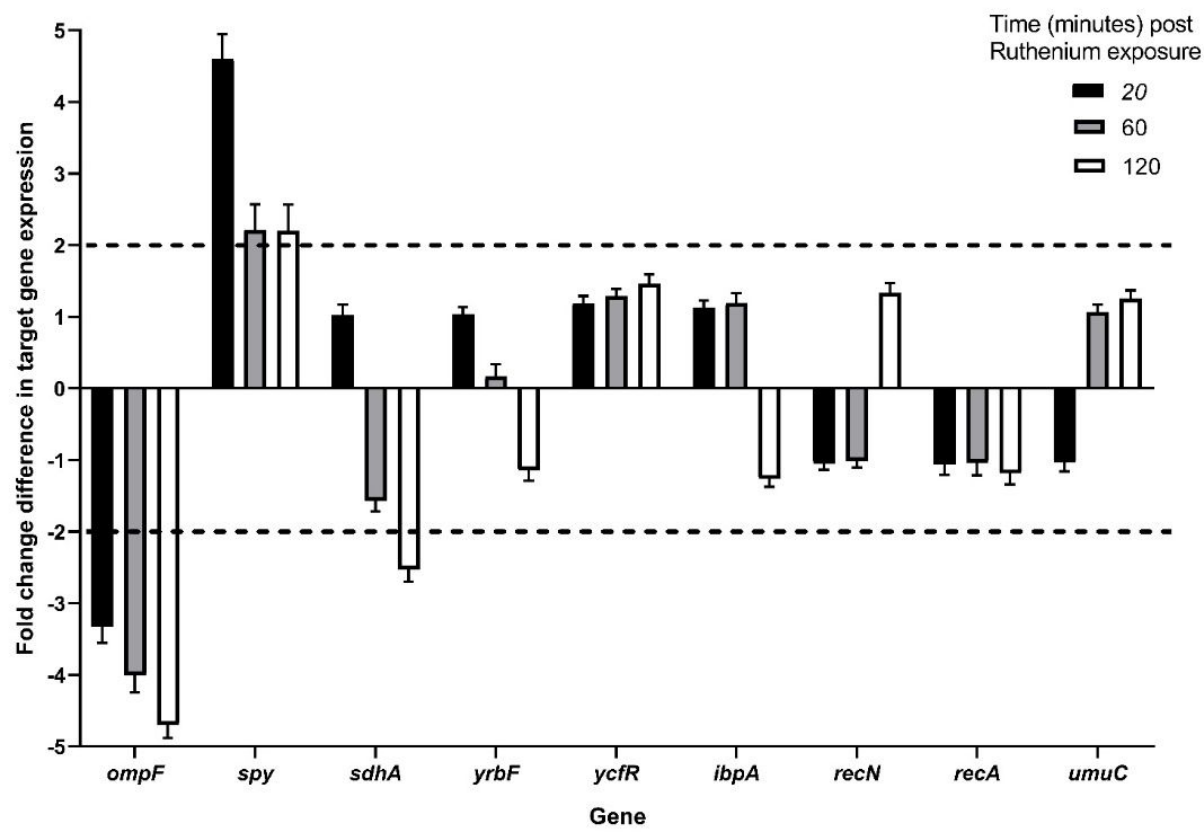

Figure 5. Relative E. coli gene expression levels of nine target genes after exposure to $\mathbf{1}^{4+}$ show effects on membrane permeability and protein repair. The qPCR expression profiles of nine genes after exposure to $1.5 \mu \mathrm{M}^{4+}$ are shown over a time course of 20(black bars), 60- (grey bars) and 120-minutes (white bars). N $\geq 3$ \pm SEM. Expression levels were normalised against reference gene 
hcat. Dashed horizontal lines represent significant expression changes ( $\geq 2$-fold change).

A steady decrease in expression of the ompF gene was observed across the time-course. This gene encodes a non-specific porin found within E. Coli57 and its primary function is facilitate passive diffusion of small hydrophilic molecules, including tetracycline and fluoroquinolones, across the cell membrane.57,58 Therefore, downregulation of this gene upon exposure to $\mathbf{1}^{4+}$ suggests an attempt by the cell to prevent uptake of the compound by reducing membrane permeability. However, exposure of a wild type E. coli strain and several porin knock-out mutants, including ompF and ompF-ompC deletions ${ }^{59}$ to $\mathbf{1}^{4+}$ showed no significant change in the minimal inhibitory or bactericidal concentrations (Figure $\mathrm{S}-2)$

Raised expression of the chaperone gene spy was observed over the time-course, with initial rapid growth in expression slowly plateauing at a constant, increased level. These observations suggest that the spy protein is rapidly required after exposure to $\mathbf{1}^{4+}$. In Gram-negative bacteria, changes in external environment can potentially affect the periplasmic space, resulting in unfavorable conditions that cause proteins to aggregate and/or unfold and in these circumstances chaperones like spy are vital in maintaining protein folding homeostasis.60,61

ACS Paragon Plus Environment 
A significant decrease in expression of the $s d h A$ gene was observed after 120-minutes exposure to $\mathbf{1}^{4+}$. The succinate dehydrogenase flavoprotein subunit, encoded by the sdhA gene, is a key protein involved in the tricarboxylic acid cycle; generation of precursor metabolites and aerobic respiration. Genes coding for key components of aerobic respiration have previously shown to be highly downregulated in E. coli when treated with another ruthenium-containing compound. ${ }^{62}$

To determine the wider effects of exposure to $\mathbf{1}^{4+}$, three other genes were tested for changes in expression after exposure. These were; the yrbF gene that encodes for a component of an ATP-binding cassette transporter system that maintains lipid asymmetry in the outer membrane which can be disrupted by chemicals or assembly defects ${ }^{63}$ ibpA that encodes for a small heat shock protein that protects various proteins from thermal and oxidative stress ${ }^{64}$, and ycfR that encodes for a protein considered as both a biofilm regulator and multi-stress response protein whose expression increases as a result of multiple environmental changes ${ }^{65}$. However, the expression levels of none of these genes altered significantly (by two-fold or greater) upon exposure to $\mathbf{1}^{4+}$.

\section{$1^{4+}$ shows antimicrobial activity of against different strains of pathogenic bacteria}

Given that antimicrobial resistance is a serious problem across many species of pathogenic bacteria, and it is not always possible to know the identity of the infecting pathogen prior to initiating 
treatment, it is important to understand the spectrum of activity of $\mathbf{1}^{4+}$. As our previous work has indicated that this complex appears to be more active in Gram-negative bacteria, ${ }^{47}$ we explored its activity against a wider spectrum of multidrug and pandrug resistant E. Coli strains as well as other Gram-negative pathogenic species- Table 2. The E. coli strains include a KPC-producing (Klebsiella pneumonia carbapenase) E. Coli², an avian pathogenic E. Coli, the E. Coli EC958 strain (for comparison) and an antimicrobial testing control strain NCTC 12923. The other Gramnegative pathogens included in this panel were clinical isolates of Pseudomonas aeruginosa, Salmonella kedougou, Shigella flexneri, Enterobacter hormaechei, Citrobacter koseri and Acinetobacter baumannii. Interestingly, the potent activity of $\mathbf{1}^{\mathbf{4}}$ against the control strain is retained in all the tested drug resistant strains, including carbapenem resistant pathogens, indicating its broad spectrum of activity.

Table 2. Minimum inhibitory concentration for $1^{4+}$ demonstrate significant antimicrobial activity against a variety of bacterial pathogens

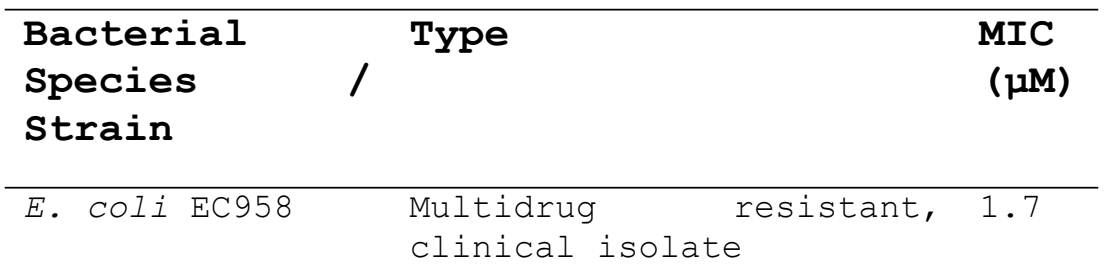

ACS Paragon Plus Environment 


\begin{tabular}{|c|c|c|}
\hline E. Coli NCTC12923 & $\begin{array}{l}\text { Antimicrobial } \\
\text { strain }\end{array}$ & 2.4 \\
\hline $\begin{array}{l}\text { E. } \\
\text { EC_160_KPC2 }\end{array}$ & Carbapenem resistant & 2.4 \\
\hline $\begin{array}{l}\text { Avian pathogenic } \\
\text { E. Coli }\end{array}$ & Multidrug resistant & 1.6 \\
\hline P. aeruginosa & Clinical isolate & 1.9 \\
\hline K. pneumoniae & Clinical isolate & 1.6 \\
\hline S. kedougou & Clinical isolate & 1.4 \\
\hline S. flexneri & Clinical isolate & 4.2 \\
\hline E. hormaechei & Clinical isolate & 1.7 \\
\hline C. koseri & Clinical isolate & 1.1 \\
\hline A. baumannii & Clinical isolate & 1.6 \\
\hline
\end{tabular}

\section{Discussion}

Examination of the antibiotic susceptibility profile of this uropathogenic $E$. coli strain demonstrates its significant multidrug resistance. Current treatment recommendations for uncomplicated urinary tract infections where antibiotic therapy is indicated include the administration of nitrofurantoin, trimethoprim / sulfamethoxazole, fluoroquinolones, fosfomycin or oral $\beta$-lactam agents. Clinicians are guided in their choice of treatment by local susceptibility patterns of $E$. coli and other uropathogens as strain specific antimicrobial susceptibility profiles are usually not determined ${ }^{66}$. The EC958 strain tested here showed resistance to several $\beta$-lactam antibiotics and both fluoroquinolones tested, however both nitrofurantoin and fosfomycin were shown to be effective (Table 2). Much of the 
antibiotic resistance profile demonstrated herein is expected when interrogating the whole genome sequence of this organism ${ }^{18}$. Totsika et al, report the presence of the pEC958 plasmid in this strain that contains multiple antibiotic resistance genes. The presence of tet $A$ and tetR found on the pEC958 plasmid provide resistance to early members of the tetracyclines, however do not confer resistance to the third-generation tigecycline tested here. 6768 Resistance to the fluoroquinolones and aminoglycosides can be explained by the presence of aac(6')-Ib-cr, encoding an aminoglycoside acetyltransferase capable of causing resistance to aminoglycosides and fluoroquinolones via modification of the drug. 697071 However, interestingly no obvious genomic explanation for rifampicin resistance could be found. Resistance to rifampicin commonly occurs via mutation of the rpoB gene and resistance is easily evolved. 72 Therefore our strain of EC958 may be a variant of the one described previously $y^{18,73}$ that has acquired this mutation. With no apparent carbapenem resistance genes in the genome sequence and EC958 displaying sensitivity to all four types tested this drug class would provide a good treatment option in the case of disease progression from EC958 causing a urinary tract infection to pyelonephritis and bloodstream infection.

Given the extensive multidrug resistance of this, and many other bacterial pathogens, new antimicrobial leads that do not readily succumb to evolving resistance are urgently needed. The rate at 
which resistance to an antimicrobial arises is dependent on its mechanism of action and whether single or multiple changes are required for significant resistance to arise. We compared the resistance changes of EC958 when exposed to $\mathbf{1}^{4+}$ with literature reports of resistance evolution in $E$. coli exposed to commonly used antibiotics. One study showed that continuous exposure to levofloxacin caused E. coli to increase resistance to this antibiotic by 16-fold within the first $24 \mathrm{~h}$ of exposure and 64fold after 14 days. The mechanism of resistance was identified as mutation of targets of the fluoroquinolone and changes in membrane permeability. ${ }^{74}$ Resistance to fluroquinolones such as levofloxacin only requires a single point mutation in DNA gyrase to emerge, so the rapid increase observed in this study is not surprising. A separate study exposed E. coli to three antibiotics: trimethoprim, chloramphenicol and doxycycline, in different evolution experiments. Trimethoprim, an antibiotic commonly used to treat urinary tract infections, showed a consistent increase in resistance of around 1,680-fold after 20 days of exposure. Increases of 870- and 10-fold were observed against chloramphenicol and doxycycline respectively ${ }^{75}$. One further study found that clinical resistance could be evolved in previously susceptible uropathogenic $E$. coli strains to ciprofloxacin, amoxacillin and aminoglycosides by as little as one, two and three to five day(s) of passage respectively ${ }^{76}$. Thus, the evolution of 
resistance to $\mathbf{1}^{4+}$ is slow in comparison to many clinically available antibiotics. The slow and low level resistance gains of EC958 against $1^{4+}$ may be due to its multi-mechanism mode of action which targets both the cell membrane and intracellular targets ${ }^{46,47}$. Therefore, it seems likely that resistant isolates would take significantly longer to arise, further adding promise to $\mathbf{1}^{4+}$ as a therapeutic tool.

In addition to gaining further insight into the potential for resistance to the $\mathrm{Ru}^{\mathrm{II}}$ complex, it is important to fully understand how $1^{4+}$ causes bacterial growth inhibition and cell death. Figure 2 demonstrates that very little impact on growth is observed within the first 30 minutes post-injection of the compound. This is in agreement with previous stimulated emission depletion imaging that identified a 20-minute period when compound accumulation at cell membranes occurs before localisation at cell poles ${ }^{46}$. Alexa Fluor NHS-ester-405 counterstaining experiments also demonstrated that membrane damage is not present within at least the first five minutes of exposure to $\mathbf{1}^{4+}$ with subsequent bacterial inner and outer membrane damage identified 60 minutes post-exposure. $\mathbf{1}^{4+}$.

To gain insight into how EC958 senses and responds to the presence of $1^{4+}$ at a transcriptomic level, we selected nine genes associated with the proposed targets of the complex; the bacterial membranes and DNA, to better understand the bacterial response to membrane damage and to determine whether DNA is a secondary target. 
We observed a steady decrease in expression of ompF upon exposure to $\mathbf{1}^{4+}$, OmpF is a non-specific porin found within $E$. coli57. This porin allows passive diffusion of small hydrophilic charged molecules and antibiotics including tetracyclines and fluoroquinolones across the cell membrane ${ }^{57}$. As downregulation of ompF causes resistance to multiple antibiotics, this change in gene expression may be a cause of the transient resistance gained during prolonged exposure to $\mathbf{1}^{4+}$ (Figure 2) ${ }^{77}$. However, with upper limits for molecular weight; the cut-off for porins of E. coli is around $600 \mathrm{Da} \cdot{ }^{78}$ As the molecular weight of $\mathbf{1}^{4+}$ is considerably larger than this, OmpF mediated transport is unlikely to be a mechanism of passage into the bacterial cell ${ }^{46}$. Aside from the generalized porins, there are solute-specific facilitated diffusion channels through the outer membrane into the periplasm that allow solutes to bypass the porin-specific size and charge requirements, $\mathbf{1}^{4+}$ may utilize one of these routes to gain entry to the $\operatorname{cell} 1^{78}$.

An increase in expression of the spy gene was observed upon exposure to $\mathbf{1}^{\mathbf{4 +}}$. Spheroplast protein Y (Spy) is a non-ATP dependent periplasmic chaperone, vital in maintaining the homeostasis of protein folding under cellular stress 60,61. In Gram-negative bacteria, such as EC958, changes in external environment impact the periplasmic space, resulting in unfavorable conditions for proteins leading to aggregation and unfolding. In these conditions 
spy expression is upregulated to help prevent unfolding and aggregation and to re-fold substrates without ATP. Stresses that have been found to cause induction in the spy gene include ethanol, indole, tannins and metals such as zinc, copper and other ruthenium-based complexes with differing mechanistic actions $62,79,80$. In this case, the upregulation of spy upon treatment with $\mathbf{1}^{4+}$ is likely due to the compound damaging the bacterial membrane and altering the conditions of the periplasmic space. Therefore, this increase in expression may be an attempt by the cell to regain the balance of protein aggregation and unfolding in this region. The expression of spy is controlled by the twocomponent systems CPxAR and BaeSR; both responsible for regulation of the envelope stress response. Accumulation of $1^{4+}$ at the poles of the cell is demonstrated herein (Figure 3C) and supports previous findings ${ }^{46}$. This transcriptomic data provides further evidence that the membrane is a major site of activity for this compound, which appears to selectively target and damage bacterial membranes but not to damage mammalian cells nor demonstrate significant toxicity in animal models at similar concentrations ${ }^{46}$. This is an important finding in the selectivity and therapeutic potential of $\mathbf{1}^{4+}$.

After two hours of exposure to $\mathbf{1}^{4+}$ a significant decrease in the expression of $S d h A$ was observed. The succinate dehydrogenase flavoprotein subunit $A(S d h A)$ is part of the succinate 
dehydrogenase enzyme complex, bound to the inner surface of the cytoplasmic membrane its primary functions are to catalyze the oxidation of succinate to fumarate in the citric acid cycle and to participate in the aerobic electron transport pathway to generate energy for the cell by oxidative phosphorylation ${ }^{81}$. At two hours $1^{4+}$ has penetrated the membranes of $E$. coli and entered the cell where it could potentially cause significant intracellular damage, therefore it is likely that treated bacteria downregulate various metabolic pathways in order to conserve energy and prevent the production of further potentially harmful species, causing the reduction in sdhA expression.

We previously showed that $\mathbf{1}^{4+}$ binds intracellular targets at 60minutes ${ }^{46,47}$. To decipher whether this binding could cause damage to bacterial DNA we monitored the regulation of three genes that would be upregulated as a response to DNA damage and the sos response: recA, recN and umuc. No significant change was observed in any of these genes suggesting that the bacteria did not produce an sos response. Therefore, at the low compound concentrations used, DNA damage is unlikely to be a target for $\mathbf{1}^{4+}$ in $E$. coli. The gene expression levels of three further proteins were examined upon exposure to $\mathbf{1}^{4+}$. The protein expressed by $y c f R$ is a biofilm regulator. It is a multi-stress response protein, expression of which increases as a result of environmental changes. ${ }^{65}$ The gene yrbF encodes for a component of an ATP-binding cassette transporter 
system, which is one mechanism that the cell may use to maintain lipid asymmetry in the outer membrane when chemically disrupted ${ }^{63}$. Finally, the heat shock protein gene, IbpA protects various substrates and proteins when the cell undergoes thermal and oxidative stress ${ }^{64}$. Interestingly, no significant change in gene expression was observed for these genes after exposure to $\mathbf{1}^{4+}$ indicting that exposure to the complex results in a relatively specific disruption to cellular function.

This gene expression data provides further evidence to support the hypothesis that the bacterial cell membrane is a significant target of $\mathbf{1}^{4+}$ with disruption to the stability of periplasmic proteins being a major stressor for the cell. The pathogen screen for sensitivity to this ruthenium complex showed significant activity against several Gram-negative species, each of these species also contain homologues of the spy and sdhA genes, so it is likely that these pathogens will elicit similar responses upon exposure (Table 2). However, the outer membrane proteins expressed by the Gram-negative pathogens differ significantly between the species tested, with $P$. aeruginosa containing a porin of unusually low permeability (OprF) and A. baumannii containing an E. coli OmpA homologue $\left(\mathrm{OmpA}_{A B}\right)$. These porins are thought to contribute to the intrinsic antibiotic resistance of these species, but as shown in Table 2 they do not appear to contribute to resistance against $\mathbf{1}^{4+}$. Recently, Smitten et al examined the differing activity of $\mathbf{1}^{4+}$ 
against Gram positive bacterial pathogens ${ }^{47}$ demonstrating that the level and type of teichoic acids present within the Gram positive cell wall has a significant impact on the antimicrobial activity of the compound. Testing antimicrobial activity of $\mathbf{1}^{4+}$ against several Gram negative bacterial species has confirmed the broadspectrum activity of this compound against Gram negative pathogens, including clinical isolates and multi-drug resistant strains (Table 2) further demonstrating the potential of this compound for future use as a therapeutic in the fight against antimicrobial resistant infections.

\section{Conclusions}

As with previous studies with $1^{4+}$ and the EC958 pathogenic strain of E. coli, it was found the compound is highly potent against several pathogenic $E$. coli strains and other Gram-negative pathogens. Although a small rise in resistance was observed over five weeks of exposure, the slow rate and relatively low level of evolution in comparison to that of clinically available organic antibiotics makes $\mathbf{1}^{4+}$ a strong potential candidate for antimicrobial therapeutics. In addition, the good kinetic solubility indicates the compound will have good bioavailability and could be used as an oral antimicrobial. Transcriptomic analysis suggests that $\mathbf{1}^{4+}$ does cause damage both to the inner and outer membrane, resulting in unfavorable, stressful conditions in the periplasmic space. Together this work adds to the growing volume 
of research supporting the hypothesis that this class of RuII complexes can be developed into effective antimicrobial drugs.

Future research will further consider the potential emergence of resistance to this lead with a particular focus on mechanisms of cellular entry and efflux and any proteins capable of binding to the complex making it unavailable to bind other more vulnerable targets within the cell. Such studies will facilitate the circumvention of these mechanism if they prove to be potential routes of resistance.

\section{Materials and Methods}

\section{Bacterial strains and culture conditions}

Strains used in this study are listed in Table 1, the primary strain used was a CTX-M-15 type extended spectrum $\beta$-lactamase (EBSL)-producing clinical isolate E. Coli EC958 (ST131) ${ }^{73}$. Bacteria were routinely grown aerobically at $37^{\circ} \mathrm{C}$ in either Mueller-Hinton broth (Sigma Aldrich, UK) or defined minimal medium with glucose as the sole carbon source (GDMM) as described previously ${ }^{46}$. Prior to experiments, bacterial starter cultures were prepared by inoculating the appropriate liquid medium with colonies from a fresh agar plate and incubation at $37^{\circ} \mathrm{C}$ with shaking at $180 \mathrm{rpm}$ for approximately $18 \mathrm{~h}$. Where necessary cultures were cryopreserved in a sterile suspension of $25 \%$ glycerol : $75 \%$ Mueller-Hinton broth $(\mathrm{v} / \mathrm{V})$ at $-80{ }^{\circ} \mathrm{C}$. 


\section{Preparation and storage of $\mathbf{1}^{4+}$}

The $1^{4+}$ compound was synthesised as previously described ${ }^{46}$. Stocks solutions of $1^{4+}$ were made to a concentration of $5 \mathrm{mg} \mathrm{ml}^{-1}$ in sterile deionised water and were stored at room temperature protected from light.

\section{Disc Diffusion Assay}

Disk diffusion assays were performed in accordance with European Committee on Antimicrobial Susceptibility Testing (EUCAST) guidelines ${ }^{53}$. After incubation the diameter of the zones of inhibition were measured and compared to EUCAST breakpoints.54,55

\section{Determination of minimal inhibitory concentrations}

MICS of $1^{4+}$ were determined via the standard broth-dilution method in 96-well microtiter plates in glucose defined minimal media. The MIC was evaluated using 2-fold decreasing concentrations of the compound between 50 to $0.09 \mu \mathrm{M}$ against starter cultures diluted to an $\mathrm{OD}_{600}$ of 0.05 - 0.1 (equivalent to a 0.5 McFarland standard). Plates were incubated at $37^{\circ} \mathrm{C}$ for 16 - $20 \mathrm{~h}$ after which the presence or absence of growth in each well was observed to determine the minimal inhibitory concentration of $\mathbf{1}^{4+}$ for each of the strains tested.

\section{Bacterial growth and viability measurements}

cultures were incubated in $250 \mathrm{ml}$ conical flasks from $2.5 \%$ starter cultures of E. Coli EC958 in $30 \mathrm{ml}$ GDMM media at $37{ }^{\circ} \mathrm{C}$ with shaking at $150 \mathrm{rpm}$. Once cultures reached an early exponential growth phase $\left(\mathrm{OD}_{600} \sim 0.4\right) \quad \mathbf{1}^{4+}$ was added at the appropriate final 
concentrations and growth monitored at regular intervals for the subsequent five hours. Viability was measured for samples harvested at the relevant time points after serial dilution in phosphate-buffered saline by plating 10 ul aliquots on MuellerHinton agar and incubation overnight at $37^{\circ} \mathrm{C}$.

\section{Structured illumination microscopy}

samples were prepared and analysed as previously described ${ }^{46}$. Briefly, E. coli cultures were grown in GDMM to an $\mathrm{OD}_{600}$ of $0.3-$ 0.4 and $1^{4+}$ was added to a final concentration of $0.8 \mu \mathrm{M}$. Samples were incubated for 0-, 20-, 60- and 120-min before washing with nitric acid and fixation with paraformaldehyde (4 \%). Localization of $1^{4+}$ in $E$. Coli EC958 cells was visualized through structured illumination microscopy using a 1516 oil and SlowFade ${ }^{\mathrm{TM}}$ Gold Antifade Mountant. Cell fluorescence was measured using ImageJ by selecting a cell and measuring area, integrated density and mean grey value. Background fluorescence was determined and corrected for in each image. Four cells were measured per image. The corrected total cell fluorescence was calculated by $\mathrm{CTCF}=$ Integrated Density - (Area of selected cell X mean fluorescence of background readings).

\section{Evolution of resistance assays}

After determination of the MIC for $\mathbf{1}^{4+}$, a 1 inoculum of starter culture incubated in GDMM was added to $10 \mathrm{ml}$ of GDMM. Compound was then added where appropriate to the culture at 0.5 times the MIC allowing growth of the strain in sub-MIC exposure. Control cultures 
were set up in the same manner in the absence of $\mathbf{1}^{4+}$. Cultures were incubated at $37^{\circ} \mathrm{C}$ and $180 \mathrm{rpm}$ for $24 \mathrm{~h}$, after which a 1 \% inoculum from this culture was used to inoculate a fresh tube of GDMM + /

- $\mathbf{1}^{4+}$. This process was repeated every $24 \mathrm{~h}$ of the lifetime of the experiment. Each week cultures were cryopreserved and re-tested for their MIC with the amount of compound added to subsequent cultures adjusted as required to maintain a 0.5 times MIC.

\section{Quantitative PCR analysis}

Cells were grown as described above in GDMM. At the designated times pre- and post- injection of a final concentration of $1.5 \mu \mathrm{M}$ $1^{4+}, 5 \mathrm{ml}$ samples of culture were removed into $10 \mathrm{ml}$ volumes of RNA Protect (Qiagen, UK) in triplicate for RNA stabilisation. RNA was extracted using the RNeasy Mini Kit from Qiagen according to manufacturer's instructions and GPCR performed as previously described $^{82}$ using a QuantStudio 3 Real Time PCR System (Applied Biosystems). Primers used for PCR can be found in supplementary information.

\section{Kinetic Turbidimetric Solubility assays}

Aqueous solubility was measured using a high throughput turbidimetric assay. A $10 \mathrm{mM}$ stock of each compound (nicardipine hydrochloride and $\mathbf{1}^{4+}$ ) were made up in DMSO. This stock was diluted in phosphate buffered saline (PBS pH 7.4) to give concentrations $(\mu \mathrm{M}): 0.4,2,4,20,40,100$ and 200. The final DMSO concentration $=1 \%$ Each concentration was plated out in triplicate. The 
solutions were incubated for $2 \mathrm{~h}$ at $37^{\circ} \mathrm{C}$ then the absorbance read on a plated reader at $620 \mathrm{~nm}$.

\title{
Statistical analyses \\ GraphPad Prism V7.05 software was used for statistical analysis tests include one-way ANOVA, two-way ANOVA With Turkey's multiple comparison tests and Welch's T-test.
}

\author{
Author contributions \\ *Corresponding authors: james.thomasesheffield.ac.uk.; \\ Samantha.mcleanentu.ac.uk \\ ¥These authors contributed equally to this manuscript
}

Supporting Information

Supporting methods: chemistry methods for $[R u(3,4,7,8$-tetramethyl1,10-phenanthroline) $\left.{ }_{2} \mathrm{Cl}_{2}\right]^{2+}, \quad\left[\left\{\mathrm{Ru}(\mathrm{TMP})_{2}\right\}_{2}(\text { tpphz })\right]^{4+}, \quad$ Anion metathesis.

Supporting data: S Table 1 - Primer sequences designed for transcriptomic analysis, $S$ Table 2 - Kinetic turbidimetric solubility plate readings, Figure S-1 - Variation in colony size of Escherichia coli after exposure to $1^{4+}$. Figure S-2 - MIC and MBC assays of Escherichia coli porin mutants, compare to the wild type.

\section{Acknowledgements}

KS is grateful to the BBRSC for a Ph.D. studentship through the White Rose Structural Biology DTP. AV is grateful to Nottingham Trent University for a PhD studentship through the Vice Chancellors Award competition. We thank our reviewers for insightful comments that have greatly improved the quality of this report.

The authors are grateful to Dr Jack C. Leo for providing omp mutant strains for testing. 


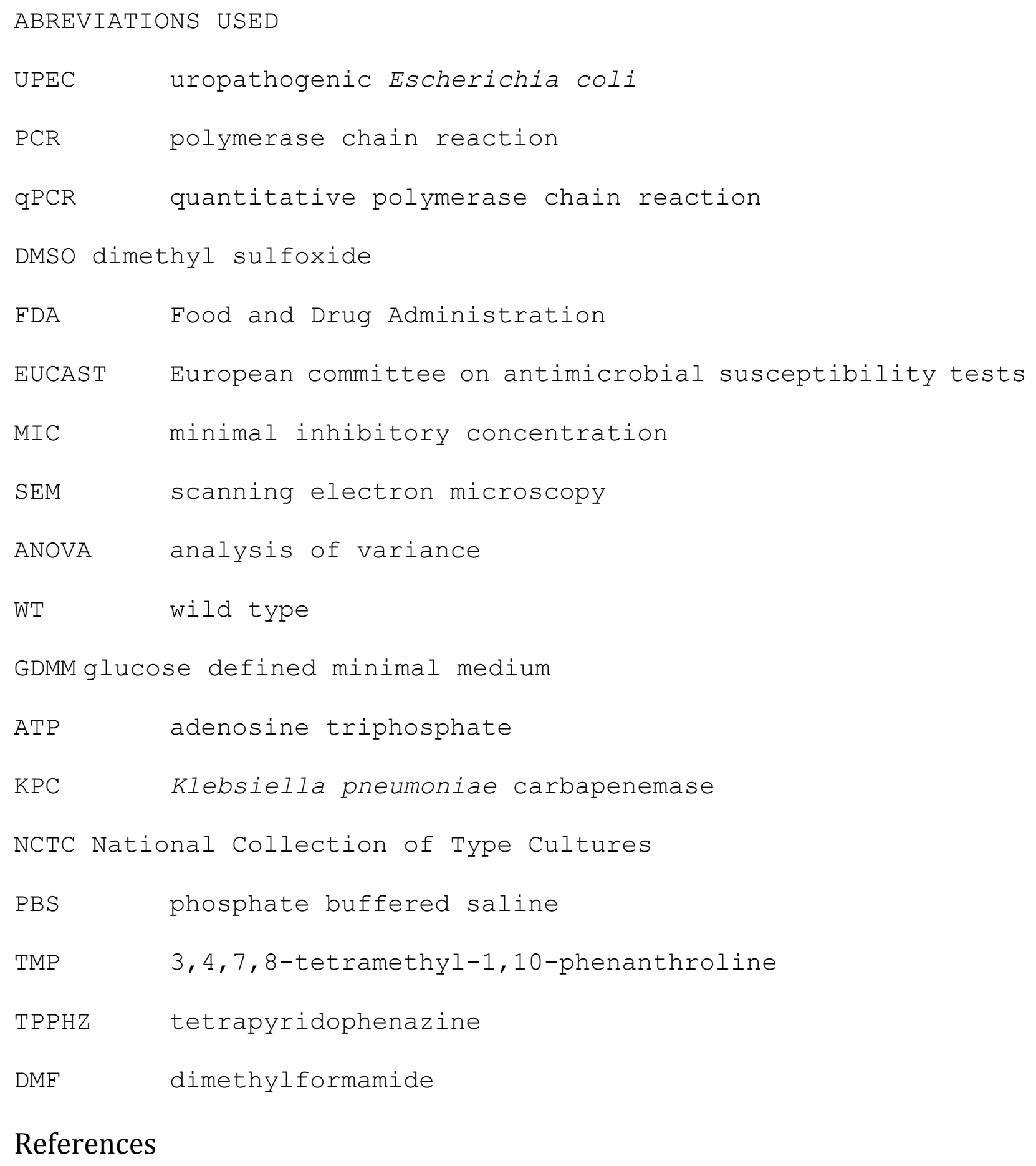

\section{References}

(1) Richter, M. F.; Hergenrother, P. J. The Challenge of Converting Gram-Positive-Only Compounds into Broad-Spectrum Antibiotics. Ann. N. Y. Acad. Sci. 2019, 1435 (1), 18-38.

(2) Tacconelli, E.; Carrara, E.; Savoldi, A.; Harbarth, S.; 
Mendelson, M.; Monnet, D. L.; Pulcini, C.; Kahlmeter, G.; Kluytmans, J.; Carmeli, Y.; Ouellette, M.; Outterson, K.; Patel, J.; Cavaleri, M.; Cox, E. M.; Houchens, C. R.; Grayson, M. L.; Hansen, P.; Singh, N.; Theuretzbacher, U.; Magrini, N.; Al-Abri, S. S.; Awang Jalil, N.; Benzonana, N.; Bhattacharya, S.; Burkert, F. R.; Cars, O.; Cornaglia, G.; Gandra, S.; Giske, C. G.; Goff, D. A.; Guzman Blanco, M.; Jinks, T.; Kanj, S. S.; Kerr, L.; Kieny, M.-P.; Leder, K.; Levy-Hara, G.; Littman, J.; Malhotra-Kumar, S.; Pan, A.; Paterson, D. L.; Paul, M.; Rodríguez-Baño, J.; Sanguinetti, M.; Sengupta, S.; Sharland, M.; Si-Mehand, M.; Silver, L. L.; Thwaites, G. E.; van der Meer, J. W. M.; Vega, S.; WechslerFördös, A.; Woodford, N.; Yilmaz, F. O.; Zorzet, A. Discovery, Research, and Development of New Antibiotics: The WHO Priority List of Antibiotic-Resistant Bacteria and Tuberculosis. Lancet Infect. Dis. 2018, 18 (3), 318-327.

(3) Nordmann, P.; Dortet, L.; Poirel, L. Carbapenem Resistance in Enterobacteriaceae: Here Is the Storm! Trends Mol. Med. 2012, $18(5), 263-272$.

(4) Paterson, D. L.; Harris, P. N. A. Colistin Resistance: A Major Breach in Our Last Line of Defence. Lancet Infect. Dis. 2015, $16(2), 1-2$.

(5) Poirel, L.; Jayol, A.; Nordmann, P. Crossm. Clin. Microbiol. Rev. 2017, 30 (2), 557-596. 
(6) Yao, X.; Doi, Y.; Zeng, L.; LV, L.; Liu, J.-H. CarbapenemResistant and Colistin-Resistant Escherichia Coli CoProducing NDM-9 and MCR-1. Lancet Infect. Dis. 2016, 16 (3), $288-289$

(7) Richter, M. F.; Drown, B. S.; Riley, A. P.; Garcia, A.; Shirai, T.; Svec, R. L.; Hergenrother, P. J. Predictive Compound Accumulation Rules Yield a Broad-Spectrum Antibiotic. Nature 2017, $545(7654), 299-304$.

(8) Deresinski, S. Methicillin-Resistant Staphylococcus Aureus: An Evolutionary, Epidemiologic, and Therapeutic Odyssey. Clin. Infect. Dis. 2005, 40 (4), 562-573.

(9) Lowy, F. D. Antimicrobial Resistance: The Example of Staphylococcus Aureus. J. Clin. Invest. 2003, 111 (9), 12651273.

o'Neill Review on Antimicrobial Resistance. Lancet Infect. Dis., 2016, 16, 767-768. Escherichia Coli. Nat. Rev. Microbiol. 2004, 2 (2), 123-140. Traditional and Emerging Pathogens. Am. J. Med. 2002, 113 Suppl, 14S-19S. Sheerin, M. S. Urinary Tract Infections: New Insights into a 
Common Problem. Postgrad. Med. J. 2005, 81 (952), 83-86. Olorunmola, F. O.; Kolawole, D. O.; Lamikanra, A. Antibiotic Resistance and Virulence Properties in Escherichia Coli Strains from Cases of Urinary Tract Infections. African J. Infect. Dis. 2013, 7 (1), 1-7.

B.; Cooperstock, M. Within-Household Sharing of a Fluoroquinolone-Resistant Escherichia Coli Sequence Type ST131 Strain Causing Pediatric Osteoarticular Infection. Pediatr. Infect. Dis. J. 2010, 29 (5), 473-475.

A.; Nichol, K.; Zhanel, G. G. Epidemic Clonal Groups of Escherichia Coli as a Cause of Antimicrobial-Resistant Urinary Tract Infections in Canada, 2002 to 2004. Antimicrob. Agents Chemother. 2009, 53 (7), 2733-2739.

(17) Cantón, R.; Coque, T. M. The CTX-M B-Lactamase Pandemic. Curr. Opin. Microbiol. 2006, 9 (5), 466-475. Totsika, M.; Beatson, S. A.; Sarkar, S.; Phan, M. D.; Petty, N. K.; Bachmann, N.; Szubert, M.; Sidjabat, H. E.; Paterson, D. L.; Upton, M.; Schembri, M. A. Insights into a Multidrug Resistant Escherichia Coli Pathogen of the Globally Disseminated ST131 Lineage: Genome Analysis and Virulence Mechanisms. PLOS One 2011, 6 (10).

Novais, ÂA.; Pires, J.; Ferreira, H.; Costa, L.; 
Montenegro, C.; Vuotto, C.; Donelli, G.; Coque, T. M.; Peixe, L. Characterization of Globally Spread Escherichia Coli ST131 Isolates (1991 to 2010). Antimicrob. Agents Chemother. 2012, $56(7), 3973-3976$.

(20)

Karlowsky, J. A.; Hoban, D. J.; DeCorby, M. R.; Laing,

N. M.; Zhanel, G. G. Fluoroquinolone-Resistant Urinary Isolates of Escherichia Coli from Outpatients Are Frequently Multidrug Resistant: Results from the North American Urinary Tract Infection Collaborative Alliance-Quinolone Resistance Study. Antimicrob. Agents Chemother. 2006, 50 (6), 2251-2254. (21) Ender, P. T.; Gajanana, D.; Johnston, B.; Clabots, C.; Tamarkin, F. J.; Johnson, J. R. Transmission of an ExtendedSpectrum-Beta-Lactamase-Producing Escherichia Coli (Sequence Type ST131) Strain between a Father and Daughter Resulting in Septic Shock and Emphysematous Pyelonephritis. J. Clin. Microbiol. 2009, 47 (11), 3780-3782. Johnson, J. R.; Johnston, B.; Clabots, C.; Kuskowski, M. A.; Castanheira, M. Escherichia Coli Sequence Type ST131 as the Major Cause of Serious Multidrug-Resistant E. Coli Infections in the United States . Clin. Infect. Dis. 2010, 51 (3) , 286-294.

Foxman, B.; Barlow, R.; D'Arcy, H.; Gillespie, B.; Sobel, J. D. Urinary Tract Infection: Self-Reported Incidence and Associated Costs. Ann. Epidemiol. 2000, 10 (8), 509-515. 
Foxman, B. The Epidemiology of Urinary Tract Infection. Nat. Rev. Urol. 2010, 7 (12), 653-660. Dwyer, F. P.; Gyarfas, E. C.; Rogers, W. P.; Koch, J. H. Biological Activity of Complex Ions. Nature 1952, 170 (4318), $190-191$.

Dwyer, F. P.; Reid, I. K.; Shulman, A.; Laycock, G. M.; Dixson, S. The Biological Actions of 1,10-Phenanthroline and 2,2'-Bipyridine Hydrochlorides, Quaternary Salts and Metal Chelates and Related Compounds. Aust. J. Exp. Biol. Med. Sci. 1969, 47 (2), 203-218. Howson, S. E.; Bolhuis, A.; Brabec, V.; Clarkson, G. J.; Malina, J.; Rodger, A.; Scott, P. Optically Pure, Water-Stable Metallo-Helical 'Flexicate' Assemblies with Antibiotic Activity. Nat. Chem. 2012, 4 (1), 31-36. Li, F.; Collins, J. G.; Keene, F. R. Ruthenium Complexes as Antimicrobial Agents. Chem. Soc. Rev. 2015, 44 (8), 25292542

K. The Microbiology of Ruthenium Complexes. Adv. Microb. Physiol. Vol 71 2017, 71, 1-96.

Viganor, L.; Howe, O.; McCarron, P.; McCann, M.; Devereux, M. The Antibacterial Activity of Metal Complexes Containing 1,10- Phenanthroline: Potential as Alternative Therapeutics in the Era of Antibiotic Resistance. Curr. Top. 
Med. Chem. 2017, 17 (11), 1280-1302.

(31)

Frei, A.; Zuegg, J.; Elliott, A. G.; Baker, M.; Braese,

S.; Brown, C.; Chen, F.; G Dowson, C.; Dujardin, G.; Jung,

N.; King, A. P.; Mansour, A. M.; Massi, M.; Moat, J.; Mohamed, H. A.; Renfrew, A. K.; Rutledge, P. J.; Sadler, P. J.; Todd,

M. H.; Willans, C. E.; Wilson, J. J.; Cooper, M. A.; Blaskovich, M. A. T. Metal Complexes as a Promising Source for New Antibiotics. Chem. Sci. 2020, 11 (10), 2627-2639.

Antibiotic Potential? Antibiotics 2020, 9 (2), 25-90.

Ramos, A. I.; Braga, T. M.; Braga, S. S. Ru(II)-Based

Antimicrobials: Looking Beyond Organic Drugs. Mini-Reviews Med. Chem. 2012, 12 (3), 227-235.

Gill, M. R.; Garcia-Lara, J.; Foster, S. J.; Smythe, C.;

Battaglia, G.; Thomas, J. A. A Ruthenium(II) Polypyridyl Complex for Direct Imaging of DNA Structure in Living Cells. Nat. Chem. 2009, 1 (8), 662-667. Sreedharan, S.; Gill, M. R.; Garcia, E.; Saeed, H. K.; Robinson, D.; Byrne, A.; Cadby, A.; Keyes, T. E.; Smythe, C.; Pellett, P.; Bernardino de la Serna, J.; Thomas, J. A. Multimodal Super-Resolution Optical Microscopy Using a Transition-Metal-Based Probe Provides Unprecedented Capabilities for Imaging Both Nuclear Chromatin and Mitochondria. J. Am. Chem. Soc. 2017, 139 (44), 15907-15913. 
Gill, M. R.; Cecchin, D.; Walker, M. G.; Mulla, R. S.; Battaglia, G.; Smythe, C.; Thomas, J. A. Targeting the Endoplasmic Reticulum with a Membrane-Interactive Luminescent Ruthenium(II) Polypyridyl Complex. Chem. Sci. 2013, 4 (12), $4512-4519$

Gill, M. R.; Derrat, H.; Smythe, C. G. W.; Battaglia,

G.; Thomas, J. A. Ruthenium(II) Metallo-Intercalators: DNA Imaging and Cytotoxicity. Chembiochem 2011, 12 (6), 877-880.

J. A.; Das, A.; Smythe, C. A Cytostatic Ruthenium(II)Platinum(II) Bis(Terpyridyl) Anticancer Complex That Blocks Entry into S Phase by Up-Regulating P27 KIP1. Chem. - A Eur. J. 2015, $21(25), 9185-9197$. Gill, M. R.; Jarman, P. J.; Halder, S.; Walker, M. G.; Saeed, H. K.; Thomas, J. A.; Smythe, C.; Ramadan, K.; Vallis, K. A. A Three-in-One-Bullet for Oesophageal Cancer: Replication Fork Collapse, Spindle Attachment Failure and Enhanced Radiosensitivity Generated by a Ruthenium(II) Metallo-Intercalator. Chem. Sci. 2018, 9 (4), 841-849. Jarman, P. J.; Noakes, F.; Fairbanks, S.; Smitten, K.; Griffiths, I. K.; Saeed, H. K.; Thomas, J. A.; Smythe, C. Exploring the Cytotoxicity, Uptake, Cellular Response, and Proteomics of Mono- and Dinuclear DNA Light-Switch Complexes. J. Am. Chem. Soc. 2019, 141 (7), 2925-2937. 
(41) Walker, M. G.; Jarman, P. J.; Gill, M. R.; Tian, X.; Ahmad, H.; Reddy, P. A. N.; McKenzie, L.; Weinstein, J. A.; Meijer, A. J. H. M.; Battaglia, G.; Smythe, C. G. W.; Thomas, J. A. A Self-Assembled Metallomacrocycle Singlet Oxygen Sensitizer for Photodynamic Therapy. Chem. - A Eur. J. 2016, $22(17), 5996-6000$. Saeed, H. K.; Archer, S.; Sreedharan, S.; Saeed, I. Q.; Buurma, N. J.; Thomas, J. A. Homo- and Heteroleptic Phototoxic Dinuclear Metallo-Intercalators Based on Ru-II(Dppn) Intercalating Moieties: Synthesis, Optical, and Biological Studies. Angew. Chemie Int. ed. English) 2017, 56 (41), 1262812633

$$
\text { Archer, S. A.; Raza, A.; Dröge, F.; Robertson, C.; Auty, }
$$

A. J.; Chekulaev, D.; Weinstein, J. A.; Keane, T.; Meijer, A. J. H. M.; Haycock, J. W.; MacNeil, S.; Thomas, J. A. A Dinuclear Ruthenium( Ii) Phototherapeutic That Targets Duplex and Quadruplex DNA. Chem. SCi. 2019, 10, 3502-3513.

$$
\text { Raza, A.; Archer, S. A.; Fairbanks, S. D.; Smitten, K. }
$$
L.; Botchway, S. W.; Thomas, J. A.; MacNeil, S.; Haycock, J. W. A Dinuclear Ruthenium(II) Complex Excited by Near-Infrared Light through Two-Photon Absorption Induces Phototoxicity Deep within Hypoxic Regions of Melanoma Cancer spheroids. J. Am. Chem. Soc. 2020, $142(10), 4639-4647$. Saeed, H. K.; Sreedharan, S.; Jarman, P. J.; Archer, S. 
A.; Fairbanks, S. D.; Foxon, S. P.; Auty, A. J.; Chekulaev, D.; Keane, T.; Meijer, A. J. H. M.; Weinstein, J.A.; Smythe, C. G. W.; Bernardino de la Serna, J.; Thomas, J. A. Making the Right Link to Theranostics: The Photophysical and Biological Properties of Dinuclear RuII-ReI Dppz Complexes Depend on Their Tether. J. Am. Chem. Soc. 2020, 142 (2), 11011111

( 46 )

Smitten, K. L.; Southam, H. M.; Bernardino de la Serna, J.; Gill, M. R.; Jarman, P. J.; Smythe, C. G. W.; Poole, R. K.; Thomas, J. A. Using Nanoscopy To Probe the Biological Activity of Antimicrobial Leads That Display Potent Activity against Pathogenic, Multidrug Resistant, Gram-Negative Bacteria. ACS Nano 2019, 13 (5), 5133-5146.

(47) Smitten, K. L.; Fairbanks, S. D.; Robertson, C. C.; Bernardino de la Serna, J.; Foster, S. J.; Thomas, J. A. Ruthenium Based Antimicrobial Theranostics - Using Nanoscopy to Identify Therapeutic Targets and Resistance Mechanisms in Staphylococcus Aureus. Chem. Sci. 2020, 11 (1), 70-79. Lipinski, C. A. Drug-like Properties and the Causes of Poor Solubility and Poor Permeability. J. Pharm. Toxicol. Methods 2000, 44 (1), 235-249. Di, L.; Fish, P. V; Mano, T. Bridging Solubility between Drug Discovery and Development. Drug Discov. Today 2012, 17 $(9-10), 486-495$. 
$(50)$ Waring, M. J.; Arrowsmith, J.; Leach, A. R.; Leeson, P. D.; Mandrell, S.; Owen, R. M.; Pairaudeau, G.; Pennie, W. D.; Pickett, S. D.; Wang, J.; Wallace, O.; Weir, A. An Analysis of the Attrition of Drug Candidates from Four Major Pharmaceutical Companies. Nat. Rev. Drug Discov. 2015, 14 (7), $475-486$ Veber, D. F.; Johnson, S. R.; Cheng, H. Y.; Smith, B. R.; Ward, K. W.; Kopple, K. D. Molecular Properties That Influence the Oral Bioavailability of Drug Candidates. J. Med. Chem. 2002, 45 (12), 2615-2623. Amidon, G. L.; Lennernäs, H.; Shah, V. P.; Crison, J. R. A Theoretical Basis for a Biopharmaceutic Drug Classification: The Correlation of in Vitro Drug Product Dissolution and in Vivo Bioavailability. Pharm. Res. 1995, 12 (3), 413-420. Testing, T. E. C. on A. S. Disk Diffusion Manual, version 6.0

https://www.eucast.org/ast_of_bacteria/disk_diffusion_method ology/. interpretation of MICs and zone diameters, version 9.0 http://wWw.eucast.org/clinical_breakpoints/. Testing, T. E. C. on A. S. Breakpoint tables for interpretation of MICs and zone diameters, version 8.0 http://www.eucast.org/clinical_breakpoints/. 
(56) Zhou, K.; Zhou, L.; Lim, Q.; Zou, R.; Stephanopoulos, G.; Too, H. P. Novel Reference Genes for Quantifying Transcriptional Responses of Escherichia Coli to Protein Overexpression by Quantitative PCR. BMC MOI. Biol. 2011, 12. (57) Vogel, J.; Papenfort, K. Small Non-Coding RNAs and the Bacterial Outer Membrane. Curr. Opin. Microbiol. 2006, 9 (6), $605-611$

(58)

Expression of OmpF and Quinolone Resistance in Escherichia Coli. J. Infect. Chemother. 2009, 15 (6), 361-366.

J. C. A New Strain Collection for Improved Expression of Outer Membrane Proteins. Front. Cell. Infect. Microbiol. 2017, 7 $(\mathrm{NOV})$.

$(60)$ Stull, F.; Koldewey, P.; Humes, J. R.; Radford, S. E.; Bardwell, J. C. A. Substrate Protein Folds While It Is Bound to the ATP-Independent Chaperone Spy. Nat. Struct. Mol. Biol. $2016,23(1), 53-58$.

R.; Navani, N. K. Genetic Regulation of Spy Gene Expression in Escherichia Coli in the Presence of Protein Unfolding Agent Ethanol. Gene 2014, 548 (1), 142-148. McLean, S.; Begg, R.; Jesse, H. E.; Mann, B. E.; Sanguinetti, G.; Poole, R. K. Analysis of the Bacterial 
Response to Ru(CO) 3Cl (Glycinate) (CORM-3) and the Inactivated Compound Identifies the Role Played by the Ruthenium Compound and Reveals sulfur-Containing species as a Major Target of CORM-3 Action. Antioxid. Redox Signal. 2013, 19 (17), 19992012 .

That Maintains Lipid Asymmetry in the Gram-Negative Outer Membrane. Proc. Natl. Acad. Sci. U. S. A. 2009, 106 (19), $8009-8014$

(64)

Escherichia Coli Small Heat Shock Proteins, IbpA and IbpB, Protect Enzymes from Inactivation by Heat and Oxidants. Eur. J. Biochem. 2002, 269 (12), 2907-2917.

(65) Deng, K.; Wang, S.; Rui, X.; Zhang, W.; Tortorello, M. Lou. Functional Analysis of YcfR and YcfQ in Escherichia Coli 0157:H7 Linked to Outbreaks of Illness Associated with Fresh Produce. Appl. Environ. Microbiol. 2011, 77 (12), 3952-3959. (66) 2018 Book 1- Infectious Diseases; American College of Clinical Pharmacy, 2018; pp 7-28. Jansåker, F.; Frimodt-Møller, N.; Sjögren, I.; knudsen, J. D. Clinical and Bacteriological Effects of Pivmecillinam for ESBL-Producing Escherichia Coli or Klebsiella Pneumoniae in Urinary Tract Infections. J. Antimicrob. Chemother. 2014, 
69 (3), 769-772.

(68)

Chopra, I.; Roberts, M. Tetracycline Antibiotics: Mode

of Action, Applications, Molecular Biology, and Epidemiology of Bacterial Resistance Tetracycline Antibiotics: Mode of Action, Applications, Molecular Biology , and Epidemiology of Bacterial Resistance. Microbiol. Mol. Biol. Rev. 2001, 65 (2), 232-260.

(69)

Rather, P. N.; Munayyer, H.; Mann, P. A.; Hare, R. S.; Miller, G. H.; Shaw, K. J. Genetic Analysis of Bacterial Acetyltransferases: Identification of Amino Acids Determining the Specificities of the Aminoglycoside $6^{\prime}-\mathrm{N}-$ Acetyltransferase Ib and IIa Proteins. J. Bacteriol. 1992, 174 $(10), \quad 3196-3203$.

(70) Ramirez, M. S.; Nikolaidis, N.; Tolmasky, M. E. Rise and Dissemination of Aminoglycoside Resistance: The Aac(6')-Ib Paradigm. Front. Microbiol. 2013, 4 (MAY), 1-13. Shaw, K. J.; Rather, P. N.; Hare, R. S.; Miller, G. H. Molecular Genetics of Aminoglycoside Resistance Genes and Familial Relationships of the Aminoglycoside-Modifying Enzymes. Microbiol. Rev. 1993, 57 (1), 138-163.

Didelot, X.; Walker, A. S.; Peto, T. E.; Crook, D. W.; Wilson, D. J. Within-Host Evolution of Bacterial Pathogens. Nat Rev Micro 2016, 14 (3), 150-162.

Forde, B. M.; Ben Zakour, N. L.; Stanton-Cook, M.; Phan, 
M.-D.; Totsika, M.; Peters, K. M.; Chan, K. G.; Schembri, M. A.; Upton, M.; Beatson, S. A. The Complete Genome Sequence of Escherichia Coli EC958: A High Quality Reference Sequence for the Globally Disseminated Multidrug Resistant E. Coli 025b:H4ST131 Clone. PLOS One 2014, 9 (8), e104400-13.

V. Continuous Culture of Escherichia Coli, under Selective Pressure by a Novel Antimicrobial Complex, Does Not Result in Development of Resistance. Sci. Rep. 2019, 9 (1), 1-11.

D. L.; Kishony, R. Evolutionary Paths to Antibiotic Resistance under Dynamically Sustained Drug Selection. Nat. Genet. 2011, $44(1), \quad 101-105$

$$
\text { Adamus-Białek, W.; Wawszczak, M.; Arabski, M.; }
$$

Majchrzak, M.; Gulba, M.; Jarych, D.; Parniewski, P.; Głuszek, S. Ciprofloxacin, Amoxicillin, and Aminoglycosides Stimulate Genetic and Phenotypic Changes in Uropathogenic Escherichia Coli Strains. Virulence 2019, 10 (1), 260-276. Gene in Esherichia Coli Mutants. Indian J. Pharm. Sci. 2013, $75(5), \quad 540-544$.

(78) Silver, L. L. Challenges of Antibacterial Discovery. Clin. Microbiol. Rev. 2011, 24 (1), 71-109. Yamamoto, K.; Ishihama, A. Characterization of Copper- 
Inducible Promoters Regulated by CpxA/CpxR in Escherichia Coli. Biosci. Biotechnol. Biochem. 2006, 70 (7), 1688-1695. Yamamoto, K.; Ogasawara, H.; Ishihama, A. Involvement of Multiple Transcription Factors for Metal-Induced Spy Gene Expression in Escherichia Coli. J. Biotechnol. 2008, 133 (2), $196-200$ of the Saccharomyces Cerevisiae Succinate Dehydrogenase: Homology Modeling, Cofactor Docking, and Molecular Dynamics Simulation Studies. J. Biol. Chem. 2004, 279 (10), 9424-9431. Flatley, J.; Barrett, J.; Pullan, S. T.; Hughes, M. N.;

Green, J.; Poole, R. K. Transcriptional Responses of Escherichia Colito S-Nitrosoglutathione under Defined Chemostat Conditions Reveal Major Changes in Methionine Biosynthesis. J. Biol. Chem. 2005, 280 (11), 10065-10072. 
For Table of Contents Use Only

Title: A transcriptomic Analysis of the Activity and Mechanism of Action of a Ruthenium(II)-Based Antimicrobial That Induces Minimal Evolution of Pathogen Resistance

Authors: Adam M Varney, Kirsty L Smitten, Jim A Thomas and Samantha McLean

Brief synopsis: Addition of the lead compound to Escherichia coli EC958 causes changes in gene expression within the cell. Expression of membrane repair protein, spy is increased whilst expression of outer membrane protein, ompF and succinate dehydrogenase, sdhA is decreased.

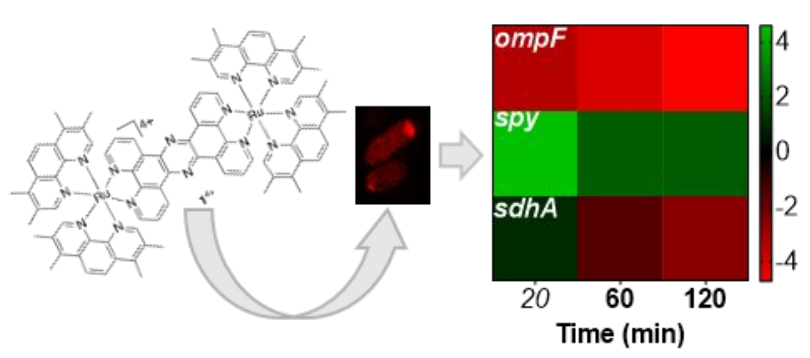

ACS Paragon Plus Environment 


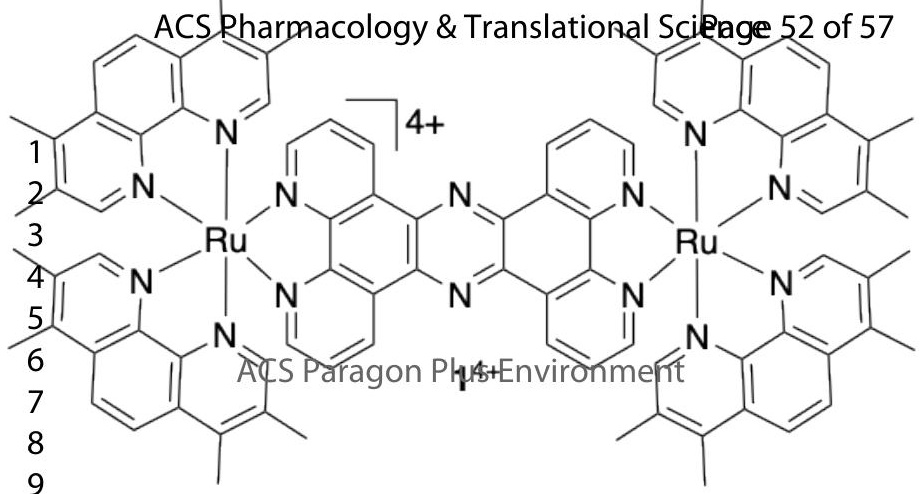


307

PageA $5 \$$ \$ $\$$ fh 87 macology \& Translational Science

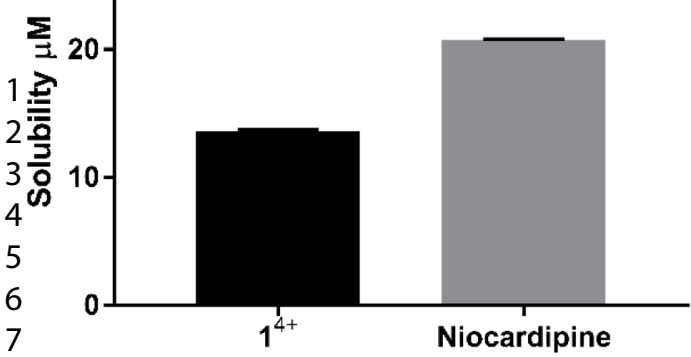

8

Compound

9

10

\begin{tabular}{|c|c|c|c|}
\hline${ }_{2}^{1}$ Compound & LogS & Solubility/ $\mu \mathrm{M}$ & Result \\
\hline $3^{1^{4+}}$ & ara.98 & uss.j.gvironment & Pass \\
\hline 4 Nicardipine & 1.318 & 20.8 & Pass \\
\hline
\end{tabular}

15 


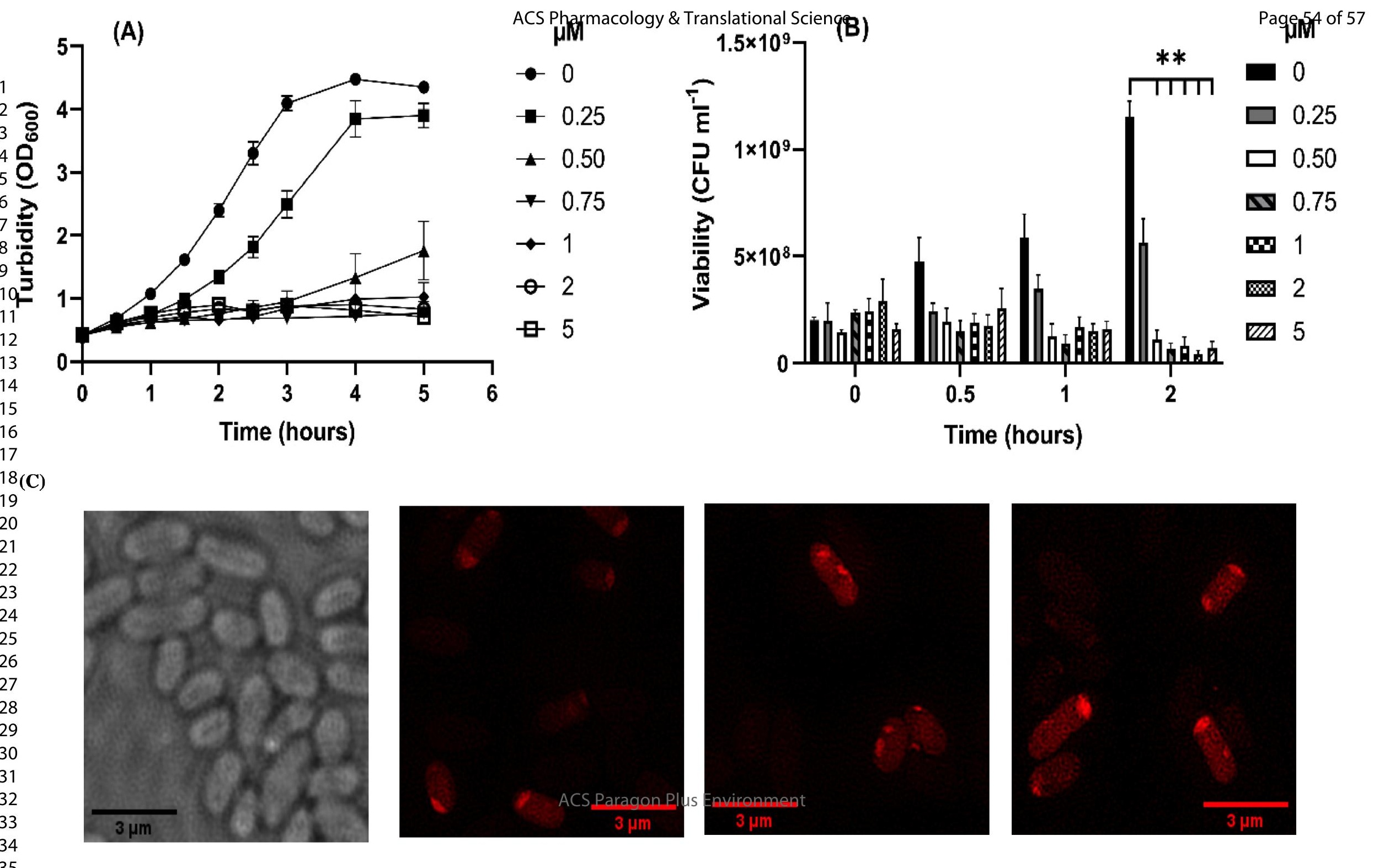




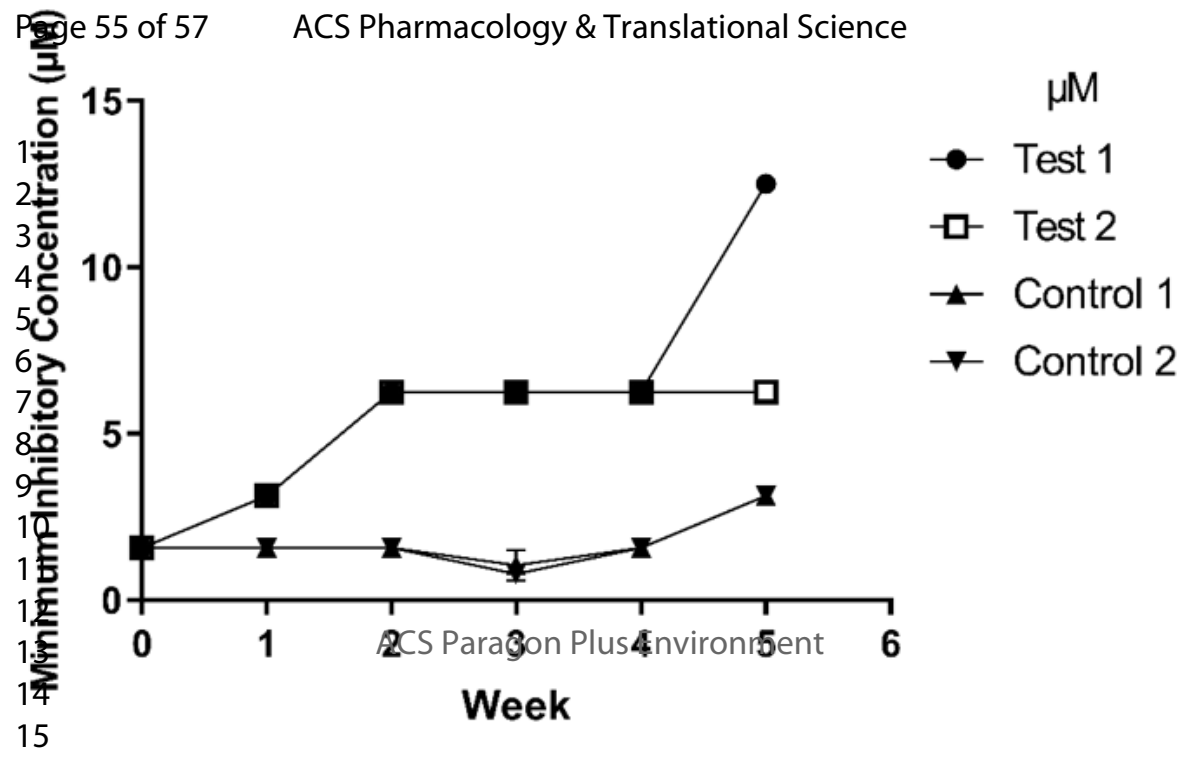




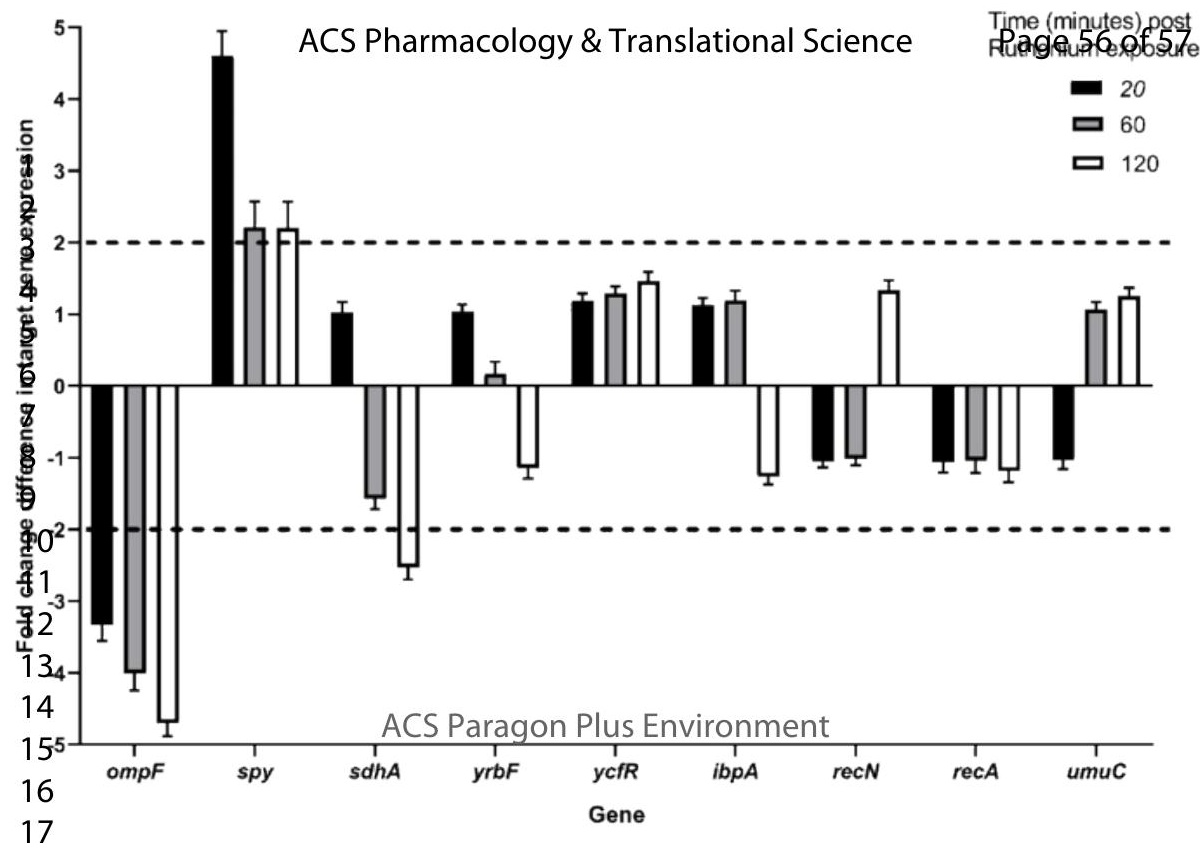




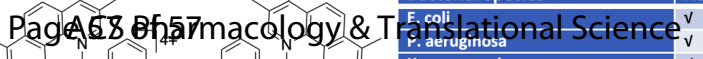

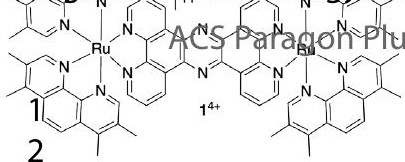

K. pneumoniae

s. hedurigon

S. flexneri

E. hormaechei

C. koseri

A. baumannif

v

Par wandanim 